OPEN ACCESS

Edited by:

William K. K. Wu,

Chinese University of

Hong Kong, China

Reviewed by:

Fotouh Mansour,

Tanta University, Egypt

Milad Ashrafizadeh,

Sabancı University, Turkey

${ }^{*}$ Correspondence:

Xiaoping Yang

xiaoping.yang@hunnu.edu.cn

Specialty section:

This article was submitted to

Pharmacology of Anti-Cancer Drugs,

a section of the journal

Frontiers in Oncology

Received: 05 October 2021 Accepted: 25 November 2021

Published: 17 December 2021

Citation:

Chu X, Bu Y and Yang X (2021)

Recent Research Progress

of Chiral Small Molecular Antitumor-

Targeted Drugs Approved by

the FDA From 2011 to 2019.

Front. Oncol. 11:785855.

doi: 10.3389/fonc.2021.785855

\section{Recent Research Progress of Chiral Small Molecular Antitumor- Targeted Drugs Approved by the FDA From 2011 to 2019}

\author{
Xuetong Chu, Yizhi Bu and Xiaoping Yang* \\ Key Laboratory of Study and Discovery of Small Targeted Molecules of Hunan Province, Department of Pharmacy, School of \\ Medicine, Hunan Normal University, Changsha, China
}

Chiral drugs usually contain chiral centers, which are present as single enantiomers or racemates. Compared with achiral drugs, they have significant advantages in safety and efficacy with high stereoselectivity. Of these drugs, chirality not only exerts influence on the solubility and pharmacokinetic characteristics but also has specific mechanistic characteristics on their targets. We noted that small molecules with unique chiral properties have emerged as novel components of antitumor drugs approved by the FDA in decade. Since approved, these drugs have been continuously explored for new indications, new mechanisms, and novel combinations. In this mini review, recent research progress of twenty-two FDA-approved chiral small molecular-targeted antitumor drugs from 2011 to 2019 is summarized with highlighting the potential and advantages of their applications. We believe that these updated achievements may provide theoretical foundation and stimulate research interests for optimizing drug efficacy, expanding clinical application, overcoming drug resistance, and advancing safety in future clinical administrations of these chiral targeted drugs.

Keywords: chiral, small molecule, antitumor-targeted drugs, recent research, FDA

\section{INTRODUCTION}

Chiral molecules first were found in 1848 , stemed from the origin of stereochemistry (1). So far, chiral compounds have covered various fields including chemical materials and pharmaceutical industry. In recent years, chiral drugs have gradually become the focus of new drug development and clinical application due to their unique profiles. Chiral small molecular targeted tumor drugs have good target binding characteristics origined from their high stereoselectivity, which can reduce the entry of inactive drugs or low-activity drugs and reduce toxic and side effects simutanuously. Thus, chiral small molecular drugs have obvious advantages and broad development prospects in antitumor-targeted therapy.

Small molecular targeted drug therapy provides more choices and survival opportunities for cancer patients who are resistant to chemotherapy, but drug resistance and safety also plague this treatment method. It is valuable to discuss the role of molecular chirality in efficacy, safety, and drug resistance from the structural characteristics of small molecular targeted drugs. Undoubtedly, the 
study of chiral structure will give more detailed explanation and supplement to the mechanism of drug action and provide reliable reference for the research and development of new drugs.

Chiral small molecular targeted anticancer drugs have become a novel component for patient treatments with twentytwo drugs approved by the FDA from 2011 to 2019. Since approved, these drugs have demonstrated their excellent therapeutic effects on patients clinically. In the meantime, their new mechanisms, new indications, and novel combination regimens have been actively explored. For example, drugs approved for the treatment of malignant hematological tumors have shown reliable efficacy in the treatment of solid tumors. Moreover, the results from either in vitro or in vivo expanded new mechanisms of action. Moving forward, the combination of chiral small molecular targeted drugs with other drugs including monoclonal antibodies shows super anticancer efficancy and safety. Profoundly, strategies to overcome drug resistance by applying these chiral targeted drugs have made a solid progress recently. Saha et al. (2) summarized the critical role of chirality on the improvement of druggability within human kinome. They pointed out that chiral kinase inhibitors have controllable and positive effects on pharmacokinetics. Chiral centers in drug molecules have specific characteristics in chiral environment, and the direct modification can optimize the efficacy of drug molecules. However, they did not focus on the recent progress of the identification of new indications, or exploration of new mechanisms of action.

In this mini review, recent clinical-related progress of new mechanisms, new indications, and novel combination regimens of twenty-two chiral small molecular antitumor-targeted drug approved by the FDA from 2011 to 2019 is summarized. The role of the chiral characteristics of these drugs will be emphasized. The advantages and disadvantages of chiral drugs will be comprehensively evaluated. At the very beginning, the basic profiles of twenty-two chiral small molecular targeted antitumor drugs are comprehensively summarized as Table $\mathbf{1 .}$ The summary diagram of this review is shown in Figure 1. The molecular structural formulas of twenty-two drugs are posted in Figure 2. Detailed information will then be presented in sequential years. We wish that the current work will establish an accurate and detailed approach for optimizing the efficacy of chiral drugs, expanding their clinical application, overcoming drug resistance and improving safety, and also provide a reliable fashion for the research of chiral drug active enantiomers.

\section{THE CHIRAL SMALL MOLECULAR TARGETED ANTITUMOR DRUGS APPROVED BY THE FDA IN 2011}

Crizotinib (1) and ruxolitinib (2) were approved by the FDA for listing in 2011, the former for nonsmall cell lung cancer (NSCLC) caused by ALK/ROS1 mutation and the latter for idiopathic myelofibrosis, postpolycythemic myelofibrosis, postpolycythemia vera myelofibrosis, polycythemia vera, and acute graft-versus-host disease. In addition, their approved chiral configuration for listing by the FDA is (R)-enantiomer.

\subsection{Crizotinib}

\subsubsection{New Mechanisms}

Crizotinib can induce the increase of E-cadherin/ROS1 synthesis mortality, leading to abnormal mitosis and multinucleation in cells with E-cadherin deficiency. The phenotype is related to cytoplasmic division deficiency and abnormal phosphorylation and localization of p120 catenin (3). In the meantime, crizotinib affects other RTK activities and makes the range of downstream targets wider $(4,5)$. On drug resistance, crizotinib inhibited cytoplasmic STAT3, led to EIF2A phosphorylation, then inhibited nuclear STAT3, and then downregulated B-cell lymphoma gene-2 (BCL-2), and finally led to a high level of protective autophagy in lung cancer cells (6). In addition, combined with afatinib, crizotinib inhibits the mTOR/insulin signaling pathway and downgrades the pRPS6KB1 and pRPS6 downstream, and then cake-specific elimination of IRS-1 nuclear signals in the signaling pathway (7).

As for (S)-crizotinib, it has the targeted inhibition of MTH1, which can destroy the homeostasis of nucleotide library, induce the increase of DNA single-strand breaks, activate DNA repair of human colon cancer cells, and effectively inhibit tumor growth in animal models. The theoretical support for the stereospecificity of (S)-enantiomer was obtained by enzyme activity assay, chemical proteomic analysis, kininome activity assay, and MTH1 eutectic structure (8). In addition, (S)-crizotinib inhibits gastric cancer cell growth through oxidative DNA damage mechanism and can trigger survival promoting AKT signal at the same time, which increase the growth rate $\gamma$-H2AX and Ser1981 phosphorylated ataxia telangiectasia-mutated gene, while $N$-acetyl-L-cysteine could inhibit this effect of (S)crizotinib. The inhibition of activated AKT will enhance the inhibitory effect of (S)-crizotinib on the growth of gastric cancer tumor cells and resensitize them (9).

It is worth noting that the two also have a certain inhibitory effect on each other's target points. (S)-crizotinib induced NSCLC cell apoptosis by increasing ROS and activating endoplasmic reticulum stress pathway, and the whole process was independent of MTH-1 (9). Thus, we can speculate that there may be an interconnection between the two inhibitory pathways.

\subsubsection{New Indications}

Compared with single-dose chemotherapy (pemetrexed or docetaxel), crizotinib has better therapeutic effect on NSCLC $(10,11)$. The satisfactory therapeutic effects of crizotinib can be observed by treating inflammatory myofbroblastic tumors with ALK rearrangement $(12,13)$ and neuroblastoma with $\mathrm{R} 1275 \mathrm{Q}$ mutation in ALK (14).

Crizotinib has potential for breast cancer with E- cadherin deficiency (3). The treatment of alveolar rhabdomyosarooma prospectively benefits from crizotinib which better solve the drug resistance during chemotherapy and radiotherapy $(4,5)$. 
TABLE 1 | Basic profiles of twenty-two chiral small molecular targeted antitumor drugs.

\begin{tabular}{|c|c|c|c|c|c|c|}
\hline $\begin{array}{l}\text { Compound } \\
\text { serial } \\
\text { number }\end{array}$ & Drugs & $\begin{array}{l}\text { Trade } \\
\text { name }\end{array}$ & $\begin{array}{l}\text { Original } \\
\text { research } \\
\text { company }\end{array}$ & Target spot & $\begin{array}{c}\text { FDA } \\
\text { approved } \\
\text { the time of } \\
\text { listing }\end{array}$ & FDA approved the indications \\
\hline 1 & Crizotinib & Xalkori & Pfizer & $\begin{array}{l}\text { ALK, c-Met, } \\
\text { ROS1, RON }\end{array}$ & $\begin{array}{l}\text { August 26, } \\
2011\end{array}$ & $\begin{array}{l}\text { August 26, 2011-NSCLC } \\
\text { March 11, 2016-NSCLC with ROS1 mutated }\end{array}$ \\
\hline 2 & Ruxolitinib & Jakav & Incyte & $\begin{array}{l}\text { JAK1/2 } \\
\text { kinase }\end{array}$ & $\begin{array}{l}\text { November } \\
16,2011\end{array}$ & $\begin{array}{l}\text { November 16, 2011-IMF, PPMF, PPV-MF } \\
\text { December 4, 2014-PV } \\
\text { April 24, 2019-aGVHD }\end{array}$ \\
\hline 3 & Carfilzomib & Kyprolis & Onyx & $\begin{array}{l}\text { N-terminal } \\
\text { threonine } \\
\text { active site of } \\
20 S \text { protease }\end{array}$ & $\begin{array}{l}\text { July } 20 \\
2012\end{array}$ & July 20, 2012-refractory MM \\
\hline 4 & Afatinib & Gilotrif & $\begin{array}{l}\text { Boehringer- } \\
\text { Ingelheim }\end{array}$ & ErbB1/2/4 & $\begin{array}{l}\text { July 17, } \\
2013\end{array}$ & $\begin{array}{l}\text { July } 17,2013-\text { NSCLC of missing EGFR exon } 19 \text { or the alternative mutation } \\
\text { of exon } 21 \\
\text { April } 15,2016-\text { metastatic NSCLC of nonresistant rare EGFR mutations }\end{array}$ \\
\hline 5 & Ibrutinib & Imbruvica & $\begin{array}{l}\text { Johnson \& } \\
\text { Johnson and } \\
\text { Pharmacyclics }\end{array}$ & $\begin{array}{l}\text { The active site } \\
\text { Cys- } 481 \text { of } \\
\text { BTK }\end{array}$ & $\begin{array}{l}\text { November } \\
13,2013\end{array}$ & $\begin{array}{l}\text { November 13, 2013-MCL } \\
\text { February 12, 2014-CLL } \\
\text { July 28, 2014-CLL carrying del 17p deletion mutations } \\
\text { January 29, 2015-WM } \\
\text { March 4, 2016-first-line treatment of CLL } \\
\text { May 6, 2016-benendamostetin + rituximab (BR) for the treatment of SLL } \\
\text { January 19, 2017-MZL } \\
\text { August 27, 2018-combined with rituximab for the treatment of LPL } \\
\text { August 3, 2017-cGVHD } \\
\text { January 28, 2019-combined with otuzumab (Gazyva) for treating adult } \\
\text { patients with newly diagnosed CLL/SLL } \\
\text { April 21, 2020-combined with rituximab for initial treatment in adult patients } \\
\text { with CLL/SLL }\end{array}$ \\
\hline 6 & Idelalisib & Zydelig & Gilead science & PI3K & $\begin{array}{l}\text { July } 23 \text {, } \\
2014\end{array}$ & July 23, 2014-FL/SLL/in conjunction with rituximab for the treatment of CLL \\
\hline 7 & Ixazomib & Ninlaro & $\begin{array}{l}\text { Takeda } \\
\text { Pharmaceutical }\end{array}$ & $\begin{array}{l}\text { The } \beta 5 \\
\text { subunit of } \\
20 S \\
\text { proteasomes }\end{array}$ & $\begin{array}{l}\text { November } \\
29,2015\end{array}$ & $\begin{array}{l}\text { November 29, 2015-in combination with lenalidomide and dexamethasone } \\
\text { for patients with MM }\end{array}$ \\
\hline 8 & Sonidegib & Odomzo & $\begin{array}{l}\text { Novartis, } \\
\text { Switzerland }\end{array}$ & $\mathrm{SMO}$ & $\begin{array}{l}\text { July } 24 \text {, } \\
2015\end{array}$ & $\begin{array}{l}\text { July } 24,2015-\text { local advanced basal cell cancer that has recurred after or is } \\
\text { not suitable for surgery or radiotherapy }\end{array}$ \\
\hline 9 & Cobimetinib & Cotellic & $\begin{array}{l}\text { Roche's } \\
\text { Genentech }\end{array}$ & MEK & $\begin{array}{l}\text { November } \\
10,2015\end{array}$ & $\begin{array}{l}\text { November 10, 2015-atezolizumab + cobimetinib + vemurafenib for the joint } \\
\text { treatment of late melanoma with BRAF V600 mutations }\end{array}$ \\
\hline 10 & Niraparib & Zejula & TESARO & PARP-1/2 & $\begin{array}{l}\text { March 27, } \\
2017\end{array}$ & $\begin{array}{l}\text { March } 27,2017 \text { - maintenance treatment for patients with recurrent ovarian, } \\
\text { tubal, or primary peritoneal cancer completely or partially relieved after } \\
\text { platinum chemotherapy } \\
\text { October 23, 2019-advanced ovarian, tubal, or primary peritoneal cancer } \\
\text { (carrying PARP mutations) that have received } 3 \text { or more chemotherapy } \\
\text { options } \\
\text { April 29, 2020-first-line maintenance treatment (whether or not PARP } \\
\text { mutations) in patients with advanced ovarian, tubal, or primary peritoneal } \\
\text { cancer after first-line platinum chemotherapy }\end{array}$ \\
\hline 11 & Acalabrutinib & Calquence & AstraZeneca & BTK & $\begin{array}{l}\text { October } \\
31,2017\end{array}$ & October 31, 2017-CLL/SLL \\
\hline 12 & Midostaurin & Rydapt & Novartis & $\begin{array}{l}\text { Protein kinase } \\
\mathrm{C} \alpha(\mathrm{PKC} \alpha)\end{array}$ & $\begin{array}{l}\text { April 28, } \\
2017\end{array}$ & April 28, 2017-ASM/SM-AHN/MCL \\
\hline 13 & Encorafenib & Braftovi & Novartis & BRAF & $\begin{array}{l}\text { June } 27 \\
2018\end{array}$ & $\begin{array}{l}\text { June } 27,2018-- \text { unresectable or metastatic melanoma patients with BRAF } \\
\text { V600E or BRAF V600K mutation confirmed } \\
\text { April } 8,2020-\text { mCRC with BRAF V600E mutation }\end{array}$ \\
\hline 14 & Ivosidenib & Tibsovo & $\begin{array}{l}\text { Agios } \\
\text { Pharmaceuticals }\end{array}$ & Mutant IDH1 & $\begin{array}{l}\text { July } 20 \text {, } \\
2018\end{array}$ & $\begin{array}{l}\text { July 20, 2018-R/R AML in human with IDH1 mutation } \\
\text { May 2, 2019-AML patients aged } 75 \text { and over who could not use intensive } \\
\text { chemotherapy due to other complications }\end{array}$ \\
\hline 15 & Duvelisib & Copiktra & Verastem & $\mathrm{PI3K}$ & $\begin{array}{l}\text { September } \\
24,2018\end{array}$ & September 24, 2018-R/R CLL/SLL/FL \\
\hline 16 & Talazoparib & Talzenna & Pfizer & PARP & $\begin{array}{l}\text { October } \\
17,2018\end{array}$ & $\begin{array}{l}\text { October } 17,2018 \text {-locally advanced or metastatic breast cancer with BRCA } \\
\text { mutation (harmful or suspected harmful) and HER2 negative }\end{array}$ \\
\hline 17 & Lorlatinib & Lorbrena & Pfizer & ALK & $\begin{array}{l}\text { November } \\
2,2018\end{array}$ & November 2, 2018-ALK-positive metastatic NSCLC \\
\hline
\end{tabular}


TABLE 1 | Continued

\begin{tabular}{|c|c|c|c|c|c|c|}
\hline $\begin{array}{l}\text { Compound } \\
\text { serial } \\
\text { number }\end{array}$ & Drugs & $\begin{array}{l}\text { Trade } \\
\text { name }\end{array}$ & $\begin{array}{l}\text { Original } \\
\text { research } \\
\text { company }\end{array}$ & Target spot & $\begin{array}{l}\text { FDA } \\
\text { approved } \\
\text { the time of } \\
\text { listing }\end{array}$ & FDA approved the indications \\
\hline 18 & Larotrectinib & Vitrakvi & $\begin{array}{l}\text { Bayer and Loxo } \\
\text { Oncology }\end{array}$ & TRKs & $\begin{array}{l}\text { November } \\
26,2018\end{array}$ & $\begin{array}{l}\text { November 26, 2018-adult and child patients with locally advanced or } \\
\text { metastatic solid tumors with NTRK gene fusion }\end{array}$ \\
\hline 19 & Glasdegib & Daurismo & Pfizer & $\mathrm{SMO}$ & $\begin{array}{l}\text { November } \\
2,2018\end{array}$ & $\begin{array}{l}\text { November } 2,2018-- \text { in combination with low-dose cytarabine for the } \\
\text { treatment of untreated } A M L\end{array}$ \\
\hline 20 & Zanubrutinib & Brukinsa & $\begin{array}{l}\text { Baekje } \\
\text { Shenzhou }\end{array}$ & BTK & $\begin{array}{l}\text { November } \\
15,2019\end{array}$ & November 15, 2019-R/R MCL \\
\hline 21 & Darolutamide & Nubeqa & $\begin{array}{l}\text { Bayer } \\
\text { Pharmaceuticals }\end{array}$ & $\begin{array}{l}\text { Androgen } \\
\text { receptor }\end{array}$ & $\begin{array}{l}\text { July } 30 \\
2019\end{array}$ & July 30, 2019-NM-CRPC \\
\hline 22 & Alpelisib & Piqray & Novartis & PI3K & $\begin{array}{l}\text { May 4, } \\
2019\end{array}$ & $\begin{array}{l}\text { May 4, 2019-combined with Fulvestrant in the treatment of advanced } \\
\text { metastatic breast cancer with hormone receptor positive (HR+)/human } \\
\text { epidermal growth factor receptor } 2 \text { negative (HER2-) and PIK3CA mutation } \\
\text { in male and postmenopausal women }\end{array}$ \\
\hline
\end{tabular}

\subsubsection{Novel Combination Regimens}

The study of animal model found that autophagy inhibitor HCQ, drug inhibitor, or shRNAs against Beclin-1 can enhance the antitumor activity of crizotinib (6). In addition, the combination of AKT inhibition and (S)-crizotinib has the potential to become a new clinical scheme for the treatment of gastric cancer (9). Beyond that, the combination of afatinib and crizotinib hopefully becomes a new treatment of disseminated cutaneous malignant melanoma (7).

\subsection{Ruxolitinib}

\subsubsection{New Mechanisms}

JAK2 has preferential selectivity to (R)-enantiomers of ruxolitinib and its aniline derivative. Their (S)-enantiomers adjust to JAK2 by rotating, which still does not fit well. This demonstrates that the chirality center is the key to a combination with JAK2. Similarly, the achiral analog barcitinib shows the same conformation as ruxolitinib in the binding mode with JAK2. In a word, the structure-activity relationship of ruxolitinib is supposed to be a core in the study of curative effect. On account of the high selectivity of ruxolitinib for JAK2, patients whose diseases caused by JAK2 mutation may benefit more from ruxolitinib combination therapy, which encourages that gene mutation detection is applied to patients.

Ruxolitinib plays a momentous part in signal transduction of erythropoietin and thrombopoietin, thus ruxolitinib can cause dose-dependent anemia and thrombocytopenia, which can be predictable $(15,16)$. In addition, the dose is adjusted on the basis of the actual situation when patients have kidney function damage (17). Ruxolitinib passes through IFN- $\gamma$-dependent and IFN- $\gamma$-independent mechanisms inhibiting inflammation, activation, and tissue infiltration of $\mathrm{T}$ cells and some undetected neutrophils (18).

\subsubsection{New Indications}

The use of ruxolitinib before hematopoietic stem cell transplantation can improve the success rate of transplantation (19).

The preliminary clinical research data (20) show that ruxolitinib is positive, well tolerated and controllable in the treatment of five hemophagocytic lymphohistiocytosis patients with secondary hemophagocytic lymphohistiocytosis. In addition, ruxolitinib can participate in the immune regulation of COVID-19 patients and reduce symptoms, but the research results did not show that ruxolitinib can reduce virus $(21,22)$.

\subsubsection{Novel Combination Regimens}

There are some debates in the effect of ruxolitinib on prolonging the survival of patients with myelofibrosis (23). It seems that novel combination regimens of ruxolitinib are a reliable approach to optimizing both efficacy and safety. The favorable efficacy and safety of the combination have been proved. In addition, ruxolitinib combined with danazol or TPD is a good therapy in elevating hemoglobin (Hgb) and platelets (PLT) $(23,24)$.

\section{THE CHIRAL SMALL MOLECULAR TARGETED ANTITUMOR DRUG APPROVED BY THE FDA IN 2012}

Carfilzomib (3) was approved by the FDA for listing in 2012, for patients with multiple myeloma who had received at least 2 drugs prior to treatment, which contains five chiral centers.

\subsection{Carfilzomib}

\subsubsection{New Mechanisms}

Carfilzomib has the less nontargeted effects so as to exert lower neurotoxicity and higher safety, as the second proteasal inhibitor approved by the FDA (25-27). In addition, vorinostat and the histone deacetylase inhibitor both inhibit phase G2/M, while increasing ROS level in the cellular environment, and mitogenactivated protein kinase (MAPK), such as stress activase JNK, p38MAPK, which also promotes the lethality of carfilzomib and vorinostat to cancer cell. Also, there is likely an amplification loop between ROS and p38MAPK (28). Combined with XPO1mediated nuclear output inhibitors, carfilzomib could interfere with the biosynthesis of ribosomes and inhibit survivalpromoting kinase PRAS40, and then achieve anticancer effects. Beyond that, in virtue of BET inhibitors, the ability of 


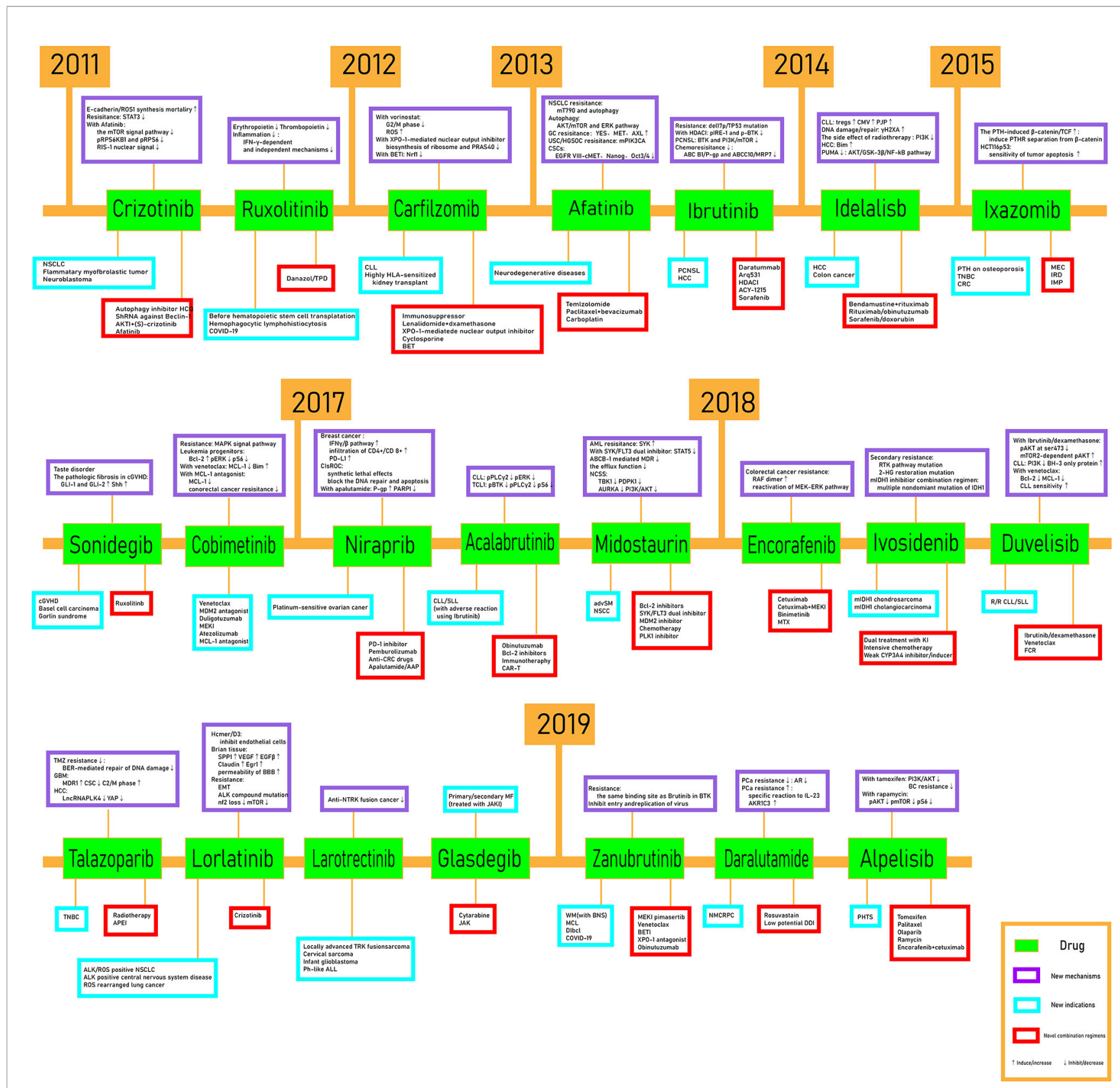

FIGURE 1 | The schematic figure.

transcription factor Nrf1 to induce proteasal genes to proteasal inhibition is weakened, hindering the rebound reaction of proteasal activity, which is the key pathway for cells to address protein toxic stress. BET inhibitors have the potential to combine with carfilzomib to treat solid tumors (29).

In safety, carfilzomib causes the myocardial activation of PP2A, then deactivates AMPKoand the downstream signaling related to autophagy, and results in the acute cardiac dysfunction. Metformin can offer the cardiprotection by recovering the phosphorylation of $A M P K \alpha$. It is also speculated that nephrotoxicity may be caused by the potential effects of carfilzomib on renal endothelial cells, or may have similar pathologic mechanisms to cardiovascular toxicity (30).

\subsubsection{New Indications}

Carfilzomib targets more selectively the chymotrypsin-like activity of the proteasome than bortezomib, which has been observed to have a certain therapeutic effect on bortezomib resistance cells and patients in vivo and in vitro (31-33). Also, carfilzomib can be used in the treatment of chronic lymphacytic leukemia, and a heterogeneous response and a variability have been observed among patients (34). In the meantime, carfilzomib 


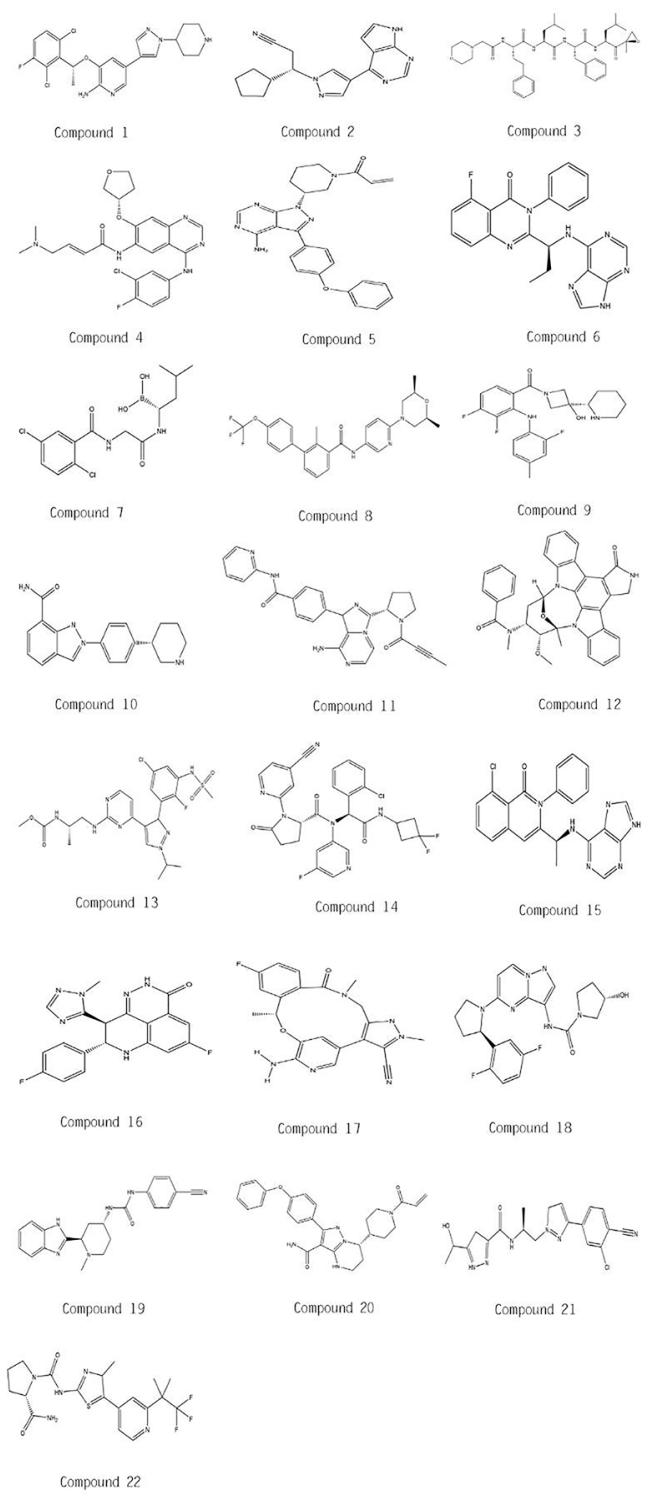

FIGURE 2 | Molecular chemical structures of twenty-two drugs.

as a candidate in highly HLA-sensitized kidney transplant showed good safety and lower toxicity, and significantly reduced levels in bone marrow plasma cells and anti-HLA antibodies (35).

\subsubsection{Novel Combination Regimens}

Favorable activity and safety have been observed in the treatment of newly diagnosed multiple myeloma (NNMM) applying carfilzomib combined with immunosuppressor. The new combination regimen of the three drugs, carfilzomib, lenalidomide, and dexamethasone, will be highly valuable (36). In addition, carfilzomib combined with XPO1-mediated nuclear output inhibitors can show up a satisfactory effect for the treatment of adiposarcoma. High-throughput screening points out that the combination of carfilzomib and cyclosporine has the potential to resisit adiposarcoma (37). Importantly, a synergy between carfilzomib and bromodomain extra-terminal (BET) family protein inhibitors can be used jointly for a variety of solid tumors (29).

\section{THE CHIRAL SMALL MOLECULAR TARGETED ANTITUMOR DRUGS APPROVED BY THE FDA IN 2013}

Afatinib (4) and ibrutinib (5) were approved by the FDA to its list in 2013, the former for the metastatic NSCLC of missing EGFR exon 19 
or the alternative mutation of exon 21 or nonresistant rare EGFR mutations (L861Q, G719X, S768I), and the latter for mantle cell lymphoma, chronic lymphocytic leukemia, fahrenheit giant globinemia, small lymphocytic lymphoma (as monotherapy or combined with benendamostetin + rituximab), recurrent refractory borderline lymphoma, chronic graft antihost disease, and rare lymphoplasmic cell lymphoma (combined with rituximab). (S)Afatinib and (R)-ibrutinib are the active enantiomers.

\subsection{Afatinib}

\subsubsection{New Mechanisms}

T790M mutation and autophagy are perceived as the main mechanism that results in the resisitance of EGFR-mutant advanced NSCLC when using the tyrosine kinase inhibitor, afatinib. In vitro, afatinib induces the autophagy, which can show higher cytotoxicity when the autophagy was suppressed by chloroquine (CQ) and 3-MA. Futhermore, the autophagy induced by afatinib needs the paticipation of Akt/mTOR and Erk signaling pathways and ROS. The results of studies in vivo are the same $(38,39)$. A naphquinone compound shikonin plays a good role in inducing apoptosis and has a negative regulation on the PI3K/AKT signaling pathway, which is also considered a possible mechanism for shikonin with anti-NSCLC activity (40).

Afatinib induces the activation of MET and AXL in HER2driven resistant gastric cancer cell lines, which can be inhibited by cabozantinib so as to reduce resisitance. YES1, a member of the Src family, is inhibited by dasatinib so that the resisitance is attenuated. Obviously, YES1, MET, and AXL activation in HER2-driven gastric cancer cells is a new mechanism for producing resistance, while the use of the corresponding activation inhibitor is a reliable method (41).

Abnormal expression of gene products commonly caused by amplification/mutation of HER2 and PIK3CA in high-grade serum endometrial cancer (USC) and ovarian cancer (HGSOC) and PIK3CA mutations are likely results of afatinib resistance, which can be overcome by HER2 combined with PIK3CA, AKT, or MTOR inhibitors. Also, the examination of PIK3CA/PIK3R1 carcincinogenic mutations may be the basis for determining whether the patient has afatinib single treatment resistance (42).

EGFRvIII/AKT, EGFRvIII/JAK2/STAT3, and focal adhesion kinase (FAK) are closely related with afatinib playing anticancer roles. EGFRvIII-cMET crosstalk in chemoradiation-resistant cancer stem cells (CSCs) is specifically inhibited by afatinib, thus inhibiting the expression of Nanog and Oct3/4 as well. In vitro experiments show that afatinib combined with temozolomide can inhibit the selfrenewal properties of Nanog and Oct3/4 (43). In addition, afatinib can block the phosphorylation of EGFR, AKT, and ERK caused by oxygen/glucose deprivation (OGD), thereby preventing the activation of subsequent pathways. Moreover, afatinib attenuated OGD-induced astrocyte activation, proliferation, and inflammasome activation, providing a reliable theoretical basis for afatinib in the treatment of neuroinflammation (39).

\subsubsection{New Indications}

Activation of EGFR was found in neurodegenerative diseases, and afatinib was found to be used in the treatment of neuroinflammatory (39).

\subsubsection{Novel Combination Regimens}

Combination of afatinib and temozolomide can cooperatively inhibit the proliferation, clonal survival, motor, invasive, and induced aging of glioblastoma (GBM) (43). Also, afatinib combined with paclitaxel and bevacizumab have a good antitumor activity, and the incidence of adverse reactions is under control (44). The favorable antitumor activity for afatinib with carboplatin and triple therapy of afatinib with carboplatin and paclitaxel are observed (45). In addition, head and neck squamous cell carcinoma (HNSCC) and the human papillomavirus (HPV) therapy with HER receptors, anti-EGFR therapies have shown that (46) afatinib monotherapy or afatinib combined with carboplatin can increase the sensitivity of cetuximab-resistant cells. Beyond that, inhibition of autophagy may address the TKI resisitance of EGFR-mutant advanced NSCLC $(38,39)$.

\subsection{Ibrutinib}

\subsubsection{New Mechanisms}

Although ibrutinib is an irreversible covalent inhibition of BTK, it showed good therapeutic effect and safety in the treatment of the first-line and relapsed/refractory CLL/SLL. In the meantime, the patients without chromosome $17 \mathrm{p}$ deletion benefits most from ibrutinib on the progression-free survival rate and overall survival. However, the long-term effects of ibrutinib on immune function of users still need further investigation $(47,48)$.

The sensitivity of ibrutinib treatment is related to unmutated igvh status and elevated zap70 expression and trisomy 12 . Meanwhile, del17p/TP53 mutation is the inherent drug resistance factor of ibrutinib cells, which is not affected by the acquired BTK and PLC $\gamma$ mutations and directly related to ibrutinib resistance (49). Arq531, a reversible BTK inhibitor, can inhibit BTK function, including B-cell receptor (BCR) signaling, activity, migration, CD40 and CD86 expression, and NF- $\mathrm{KB}$ gene transcription in vitro. Arq531 can obtain better survival rate than ibrutinib, and BCR-mediated C481S-BTK and PLC $\gamma 2$ mutations, which are directly related to ibrutinib resistance, are also inhibited by Arq531 (50). In addition, the birth of daratummab makes CD38 a research hotspot. Daratummab has a good therapeutic effect on CLL through ADCC, CDC, and ADCP, and apoptosis mechanisms CD38 reduced the enhancement effect of ibrutinib on Syk, BTK, PLC $\gamma 2$, ERK1/2, and AKT. Combined medication can target BTK and CD38 at the same time and exert a strong antiCLL effect (51).

The HDAC inhibitor combined with ibrutinib caused a significant inhibition of p-IRE1 and p-BTK, thus inhibiting the downstream target of BCR, which is the effect that drug alone does not have (52). Furthermore, inhibiting BTK and P13K/ mTOR simultaneously can enhance the therapeutic effect of ibrutinib on PCNSL with CD79B mutation (53). In the meantime, ibrutinib can also reduce the drug resistance of tumor cells to paclitaxel by inhibiting the outflow function of the ATP-binding cassette subfamily B member 1 (ABC B1/Pglycoprotein) and subfamily C member 10 (ABCC 10/MRP 7) (54). Also, ibrutinib inactivates EGFR in hepatocellular carcinoma cells and block downstream Akt and ERK signals, thus inhibiting the expression of key genes involved in cell 
proliferation, migration, and survival and activating cell differentiation (55).

\subsubsection{New Indications}

Ibrutinib has an activity in relapsed or refractory primary central nervous system lymphoma (PCNSL), which shows resistance in PCNSL treatment (53). Ibrutinib has a good therapeutic activity on hepatocellular carcinoma, including sorafenib-resistant HCC cells (55).

\subsubsection{Novel Combination Regimens}

Daratummab with ibrutinib have achieved the cancer cell killing effect in vivo and in vitro (51). Also, Arq531 has the potential to become the combination candidate drug of ibrutinib to overcome the resistance to ibrutinib (50). In addition, the participation of ibrutinib can promote the antitumor activity of paclitaxel (54).

Pan-class I/II histone deacetylase (HDAC) inhibitors can be used to treat some lymphomas, and ACY-1215 is the first selective inhibitor of HDAC. ACY-1215 plus ibrutinib is highly synergistic in lymphoma cell lines and primary human lymphoma samples. In the xenograft lymphoma model, this combination caused the tumor growth delay and prolonged the overall survival rate (52). Ibrutinib has synergistic effect with sorafenib or sorafenib homolog on apoptosis of hepatocellular carcinoma cells. In vivo test, the combination drug shows satisfactory effect and safety, and BTK + immune cells are enriched in tumor microenvironment (55).

\section{THE CHIRAL SMALL MOLECULAR TARGETED ANTITUMOR DRUGS APPROVED BY THE FDA IN 2014}

Idelalisib (6) was approved by the FDA to its list for recurrent follicular cell non-Hodgkin lymphoma (FL) and recurrent small lymphocyte lymphoma, in conjunction with rituximab for the treatment of recurrent chronic lymphocytic leukemia. (S)Idelalisib is the active enantiomer.

\subsection{Idelalisib}

\subsubsection{New Mechanisms}

High-frequency CMV reactivation and pneumocystis jiroveci pneumonia (PJP) were observed in the treatment of CLL using idelalisib. Mechanically, idelalisib impaired T-cell-mediated CMV responses and patients with gastrointestinal reactions were found to increase the percentage of Tregs in biopsy, sometimes associated with a positive PCR of infectious pathogens (56). Therefore, it can be speculated that idelalisib may have a side effect of T-cell damage that promotes infection or viral reactivation. Also, idelalisib causes impaired polymorphonuclear neutrophil (PMN) function, which in turn causes neutropenia-like susceptibility to infections (57).

Idelalisib could enhance the bendamustine-mediated DNA damage/repair response. In the meantime, $\gamma \mathrm{H} 2 \mathrm{AX}$ was separately activated and the corresponding translation process was synergfacilitated by the two drugs. A decrease in the MCL-1 total protein population in CLL cells was observed, and MCL-1deficient heterogeneous mouse embryonic fibroblasts are highly sensitive to monotherapy and combined therapy (58).

In addition, idelalisib may increase the side effects of radiotherapy. One patient developed strong grade 2 radiodermatitis and grade 3 mucositis after 20 Gy radiotherapy, and idelalisib patients who do not take idelalisib show good tolerance, with the most serious adverse reaction being no more than grade 1 radiodermatitis (59). When the irradiation intensity was $2 \mathrm{~Gy}$ and idelalisib was $100 \mathrm{nmol} / \mathrm{L}$, the radiosensitivity increased significantly, which may be directly related to the inhibitory effect of idelalisib on PI3K.

Idelalisib promotes Bim induction via the FoxO3a pathway after PI3K/AKT inactivation to induce apoptosis. This shows that Bim plays an important role in the treatment of HCC by idelalisib (60). Idelalisib induced PUMA via the AKT/GSK-3ß/ NF- $\kappa \mathrm{B}$ pathway, p53 upregulated modolator of apoptosis, belonging to $\mathrm{BH} 3$-only $\mathrm{Bcl}-2$ family, which play a key role in apoptosis in cancer cells (59). Interestingly, idelalisib can inhibit platelet aggregation mediated by ITAM receptors GPVI and CLEC-2 as well as the adhesion and was antithrombotic and bleeding at high doses (61).

\subsubsection{New Indications}

Idelalisib showed good activity in HCC cells and colon cancer cells $(59,60)$. In addition to this, idelalisib can collaborate with 5 FU or regorafenib to induce colon cancer apoptosis, with PUMA involvement in the process, which can serve as the sensitivity index of idelalisib in the treatment of colon cancer, and it is also the main factor of the role of idelalisib of anticolon cancer (61).

\subsubsection{Novel Combination Regimens}

Idelalisib + bendamustine + rituximab therapy showed greater efficacy and safety compared with bendamustine and rituximab therapy commonly used clinically to treat recurrent/refractory CLL (62). Bindem therapy by idelalisib + bendamustine produced synergistic cytotoxicity in CLL therapy (58). However, the safety evaluation of idelalisib, denidamide, and rituximab showed excessive toxicity, thus the combination is recommended in a carefully designed and diligently tested clinical trial environment (63). The results of the effect of idelalisib on the treatment of rituximab and obinutuzumab on leukemia showed that inhibition with idelalisib on PI3K did not negatively affect the efficacy of the above two McAb and had clinical value associated with them (64). Meanwhile, idelalisib and sorafenib or doxorubicin exhibit synergistic anti-HCC effects, in which the decrease of anti-HCC effect of idelalisib in Bim-deficient objects is observed (60).

\section{THE CHIRAL SMALL MOLECULAR TARGETED ANTITUMOR DRUGS APPROVED BY THE FDA IN 2015}

There were three drugs approved for listing by the FDA, including ixazomib (7), sonidegib (8), and cobimetinib (9). 
Ixazomib combination with lenalidomide and dexamethasone are approved for patients with multiple myeloma who have been treated at least one time. Sonidegib is approved for local advanced basal cell cancer that has recurred after or is not suitable for surgery or radiotherapy. Cobimetinib is approved in association with vemurafenib (or vemurafenib +atezolizumab) for melanoma with BRAF V600E or V600K mutations.

\subsection{Ixazomib}

\subsubsection{New Mechanisms}

Ixazomib enhances the activation of the PTH-induced $\beta$-catenin/ TCF signal by inducing PTHR separation from $\beta$-catenin, thus enabling the regulation of the PTHR signal to maintain the PTH anabolic effect (65). In HCT116 p53, ixazomib is induced by CHOP-dependent DR5, sensitizing the tumor apoptosis process induced by tumor necrosis factor-related apoptosis-inducing ligand (TRAIL) (66).

\subsubsection{New Indications}

In addition to treat MM approved by the FDA, ixazomib also improves the treatment effect of PTH on osteoporosis and other absorptive bone diseases (65). In the treatment of solid tumors, ixazomib showed therapeutic activity in the treatment of colorectal cancer (CRC) and triple-negative breast cancer (TNBC) (66).

\subsubsection{Novel Combination Regimens}

In the treatment of recurrent/refractory acute myeloid leukemia, the maximum tolerated dose of ixazomib with mitoxantrone, etoposide, and cytarabine (MEC) was $1.0 \mathrm{mg}$, observing the dose-dependent thrombocytopenia as the controlled toxicity, and the overall response rate reached $53 \%$, indicating that the combination drug had certain therapeutic effect (67).

The China Continuation study results support the extension of ixazomib + lenalidomide + dexamethasone (IRD) therapy in RRMM therapy worldwide (68). Also, there was also a significant association between ixazomib exposure and the adverse reactions of triple therapy, the probability of not only anemia and thrombocytopenia above level 3 but also diarrhea fatigue, nausea, peripheral neuropathy, and rash were directly related with Ixazomib exposure, which can be controlled by adjusting the dose of ixazomib, providing a reference to the clinical dose range of ixazomib (69).

In NDMM therapy, two triple therapies for Ixazomib were proposed. One is the ixazomib + RD (IRD), which shows good therapeutic efficacy and safety in patients who have not received autologous stem cell transplantation (SCT). Subsequent maintenance treatment can be treated with ixazomib alone (70). The other is the ixazomib-melphalan-prednisone (IMP) which showed good tolerance and antimyeloma activity. A single dose of ixazomib can be used for maintenance treatment in elderly NDMM patients and those who are not eligible for transplantation (71). In addition, IDR showed good therapeutic activity and safety in Waldenstrom macroglobulinemia (WM), providing a safe, simple, and effective treatment for patients with WM (72).

In vivo metabolism of ixazomib provides new ideas for its drug combination. When the concentration of ixazomib exceeds the clinical level, ixazomib was observed to be metabolically metabolized by multiple CYP isoenzymes. The effect of CYP3A inhibitors on ixazomib metabolism was not significant, which could be used directly together without adjusting to the dose of ixazomib. For strong CYP3A inducers, simultaneous administration with ixazomib should be avoided, as which significantly reduces the whole body exposure of ixazomib, somewhat reducing the efficacy of ixazomib (73). Furthermore, ixazomib with carboplatin had good treatment for TNBC and patients demonstrated good tolerance to bindem therapy in the second stage of the trial (74).

\subsection{Sonidegib}

\subsubsection{New Mechanisms}

Debilitating taste disorder was reported in patients using hedgehog pathway inhibitior (HPI). The mouse had a loss of taste after using sonidegib, but the response of the tongue did not change to tactile stimulation. Rats and mice had the same performance in neural effects in fungiform (FP), and rats were significantly more severe than mice in taste buds (TB) and circumvallate papillae (CV) (75). For patients with high-risk limited prostate states undergoing radical prostatectomy, GLI1 expression identified baseline levels of hedgehog signaling pathway activity after the use of sonidegib. Sonidegib can reach the prostate site and produce a 60 -fold hedgehog inhibition effect (76). In the human and mouse chronic graft-versus-host disease (cGVHD), the hedgehog signal is active, accumulating the transcription factors GLI-1 and GLI-2 particularly in fibroblasts, leading to the pathologic fibrosis seen in cGVHD. However, H-score for sonic hedgehog (Shh), theoretically not affected by sonidegib, showed a significant content decline in vitro, for unclear reasons (77).

\subsubsection{New Indications}

Sonidegib suppresses the hedgehog signaling pathway and is thought to be used in the adjuvant treatment of prostate cancer. However, the significance and status of sonidegib in prostate cancer have not been clarified (76). Sonidegib has the potential to treat steroid refractory cGVHD, but the patient showed obvious toxicity accumulation so as to discontinue the treatment. The sonidegib adverse reactions and the pathological characteristics of cGVHD partially overlap, and it was difficult to distinguish the specific correlation between toxicity and sonidegib. This partly limits the use of sonidegib in cGVHD (77).

In addition, sonidegib has good efficacy and safety for locally advanced basal cell carcinoma. Moreover, positive results from trials conducted in patients with Gorlin syndrome showed the possibility of using sonidegib not only for treatment of locally advanced basal cell carcinoma but also for cancer chemoprevention (78).

\subsubsection{Novel Combination Regimens}

The combination of sonidegib and ruxolitinib can produce good tolerance and safety in patients with multiple myeloma who have not used JAK inhibitors. The study identified a combined recommended phase 2 dose (RP2D) regimen for sonidegib $400 \mathrm{mg}$ daily + ruxolitinib $20 \mathrm{mg}$ twice daily. The overall benefits of combined therapy compared with ruxolitinib alone 
are relatively limited and do not have significant advantages for the treatment effect of multiple myeloma, which is a near step to extended clinical trials of sonidegib (79).

\subsection{Cobimetinib}

\subsubsection{New Mechanisms}

Using cobimetinib combined with vemurafenib for the treatment of melanola, the the MAPK signaling pathway activated by MEK is the core cause of antagonizing BRAF inhibitors (80). There is no toxicity accumulation in long-term treatment, but it was reported that (81) cobimetinib caused blurred vision and eye photophobia in the treatment of metastatic melanoma with BRAF mutations, and the symptoms were basically resolved 14 days after treatment. The specific mechanism is still unclear. In addition, cobimetinib developed very rare "dropped head syndrome" in treating patients with Erdheim-Chester Disease (ECD), which were relieved by reducing the administration dose after a period of withdrawal (82).

BCL2 protein was enriched in leukemia progenitors and that cobimetinib inhibited cytokine-induced pERK and PS6 signaling pathways. The signaling pathway downstream of MAPK is inhibited and is synergistic in apoptosis of cancer cells. Cobimetinib combined with venetoclax downgrades the content of the MCL1 protein, and the BCL2:BIM and MCL1: BIM complexes are damaged and release BIM, thus causing apoptosis of cancer cells (83). The BRAF-mediated MEK/ERKmediated MCL-1 upregulation is the production mechanism of colorectal cancer cell resistance that causes BRAF mutations. Cell experiments found that combination of cobimetinib and MCL-1 antagonists significantly inhibited growth of tumor cell growth and antagonized cell resistance (84).

Higher expression of FLT3 and MDM2 in AML cells of normal karyotype (NK) and wild-type TP53, and are therefore most sensitive to combination therapy. As a result, the content of FLT3 and MDM2 can be used as biomarkers for the combination therapy of cobimetinib and idasanutlin for AML (85).

\subsubsection{Novel Combination Regimens}

The drug combination of dabrafenib and trametinib was shown to have a therapeutic effect comparable with the drug combination of cobimetinib and vemurafenib, and the former was safer. However, the study only provided data reference for doctors (86). Cobimetinib combined with venetoclax can play the therapeutic activity against leukemia, targeting both BCL2 and MAPK pathways to induce apoptosis of cancer cells (84). In addition, cobimetinib combined with MDM2 antagonists idasanutlin showed significantly induced apoptosis in the AML cell line (85).

Duligotuzumab is a humanized monoclonal bispecific antibody that targets to inhibit HER3 and EGFR and inhibit downstream signaling of AKT and ERK. The combination of duligotuzumab and cobimetinib in the treatment of KRAS-mutated tumors showed poor resistance and limited efficacy in the subject population. However, cobimetinib and duligotuzumab as single combined with other drugs achieve better tolerance (86).

The accumulation and survival of tumor-specific $\mathrm{T}$ cells is facilitated by MEK inhibitors. In the treatment of solid tumor, the cobimetinib and PD-L1 inhibitors atezolizumab has good safety and therapeutic activity and is unaffected by KRAS/BRAF activity $(83,87)$. In mouse models of colorectal cancer with BRAF V600E mutations, cobimetinib combined with MCL-1 antagonists showed good drug-resistant antagonism (88).

\section{THE CHIRAL SMALL MOLECULAR TARGETED ANTITUMOR DRUGS APPROVED BY THE FDA IN 2017}

Niraparib (10), acalabrutinib (11), and midostaurin (12) were approved to its list by the FDA in 2017, niraparib for patients with recurrent ovarian, tubal, or primary peritoneal cancer completely or partially relieved after platinum chemotherapy. Acalabrutinib is for patients with CLL or SLL. Midostaurin is for newly diagnosed FLT3 gene mutations (combined with chemotherapy drugs) and adult aggressive systemic hypergalocytosis (ASM), systemic hypergalocytosis (SM-AHN) with blood tumors, and hypertrophic cell leukaemia (MCL). Both (S)-niraparib and (S)-acalabrutinib are active enantiomers. The active enantiomer of midostaurin is $(5 S, 6 R$, 7R, 9R)-enantiomer.

\subsection{Niraparib}

\subsubsection{New Mechanisms}

Niraparib was metabolized by hydrolysis and binding pathway, $31.6 \%$ of drugs from feces and $40.0 \%$ of drugs from urine $14 \mathrm{~h}$ after administration. About $29.9 \%$ of the fecal and urine excretion drugs are drug prototypes. According to research data, niraparib is a low liver extraction drug with high bioavailability, low clearance, and long half-life, in line with the anticancer activity of niraparib $(89,90)$. Improved time without symptoms or toxicity has been demonstrated in the niraparib-treated patients of recurrent ovarian cancer (91).

Niraparib has been shown to regulate the tumor immune microenvironment. In breast cancer cell lines and xenotransplantation models, PARP inhibitors upregulate PD-L1 expression in a tumor inherent manner, whether BCRA is mutated or not. Mechanically, niraparib can enhance the activity of the the type I (alpha) and type II (gamma) interferon pathway and increase the infiltration of CD8 + and CD4 + cells in the tumor. Meanwhile, niraparib treatment alone may cause immune memory (92). In conclusion, good cancer effects may be because niraparib increased sensitivity of the tumor to immune checkpoint blocking therapy.

TWIST may be the oncogene that promotes OC cells to cisplatin resistance. In TWIST-deficient cisplatin-resistant OC cells (CisR OC), niraparib and cisplatin have synthetic lethal effects on cancer cells. Further research reveals two potential mechanisms, one by blocking the DNA repair, which suppresses the activation of PARP1 and XRCC1. The other is mitochondrial emergency-mediated apoptosis. Cytochrome $c$ in the mitochondria is released into the cytoplasm, initiating cypasedependent apoptosis, resulting in irreversible cell death (93).

When the niraparib dose increased to $300 \mathrm{mg}$, apalutamide led to a higher incidence of dose-limiting toxicities (DLTs). In 
contrast, AAP and niraparib have better tolerance and security. The researchers speculated that apalutamide induced the metabolism of niraparib, reducing niraparib exposure or that apalutamide induced the P-glycoprotein to reduce niraparib exposure. Therefore, the efficacy of apalutamide combined with niraparib is affected (90).

\subsubsection{New Indications}

Niraparib could prolong the survival of patients with platinumsensitive recurrent ovarian cancer who responded to the last platinum chemotherapy. Furthermore, maintenance therapy with niraparib benefits regardless of the patient's response to the last platinum chemotherapy (94).

\subsubsection{Novel Combination Regimens}

Niraparib combined with PD-1 inhibitors showed good tolerance and controllable safety in the treatment of recidivity ovarian cancer (95). Meanwhile, niraparib and pemburolizumab achieved $21 \%$ objective remission and $49 \%$ in advanced or metastatic TNBC patients (96). The safety of combined treatment is controlled and has further clinical research.

Niraparib combined with three commonly used anti-CRC drugs (5-fluorouracil, oxaliplatin, or irinotecan) and the therapy of niraparib and irinotecan were the strongest (97). When niraparib and apalutamide or abiraterone acetate plus prednisone (AAP) were used to treat metastatic castrationresistant prostate cancer (mCRPC), two different combination therapies showed safety differences. Apalutamide may cause patient fatigue (90).

\subsection{Acalabrutinib}

\subsubsection{New Mechanisms}

In human CLL NSG heterhorygraft models, acalabrutinib reduces phosphorylation of PLC $\gamma 2$ and ERK and significantly inhibit CLL tumor cell proliferation. In TCL1 overrelay transfer models, acalabrutinib can inhibit phosphorylation of BTK, PLC $\gamma 2$, and S6. At concentrations below $10 \mathrm{~nm}$, ibrutinib produces varying levels of inhibition on all nine kinases containing cysteine residues, while acalabrutinib inhibition only on BTK. Acalabrutinib showed high selectivity and showed similar treatment effects to ibrutinib (98). Twice daily alone of acalabrutinib in recurrent/refractory cell lymphocyte lymphoma achieved a high percentage of overall and complete efficacy $(99,100)$.

\subsubsection{New Indications}

Acalabrutinib shows good safety and tolerance in patients with CLL or SLL who stop taking medication with adverse reactions using ibrutinib (101).

\subsubsection{Novel Combination Regimens}

In recurrent/refractory cell lymphocyte lymphomathe, the combination of acalabrutinib and obinutuzumab can further optimize the security of acalabrutinib and specifically improve the adverse events inherent in acalabrutinib (100).

The potential drug association protocol was identified by analyzing the pharmacological characteristics of CLL patients treated with acalabrutinib, in the BCL-2 inhibitor venetoclax, alkylazer bendamustine, proteassomal inhibitor carfilzomib, and nucleoside analog fludarabine, duvelisib (PI3K inhibitor). In ACP-319 (in PI3K delta inhibitor), both in vivo and in vitro experiments show that venetoclax can maximize acalabrutinib to play anticancer effect, and both the degree and safety of apoptosis of cancer cells were optimized (102).

Meanwhile, anti-CD20 antibodies combined with highly selective BTK inhibitors can achieve better anti-CLL effects. Obinutuzumab and acalabrutinib for CLL found that (103) $95 \%$ of patients previously ineffective and $92 \%$ of patients with refractory or relapse, indicating that combined therapy could achieve a high level of treatment effect, but $71 \%$ of patients had grade $3 / 4$ adverse reactions and safety requires further research. In addition, acalabrutinib monotherapy and acalabrutinib combined with obinutuzumab all showed superior treatment effects than obinutuzumab-chlorambucil (104).

Acalabrutinib combined standard care CHOP-R chemical immunotherapy (cyclophosphamide, doxorubicin, vincristine, prednisolone, and rituximab) in a new diagnosis of DLCBL type Richter's syndrome (RS) for CLL transformation (105). Clinical treatment of CD19 + B cells usually used chimeric antigen receptor (CAR) T-cell therapy. Lisocabtagene maraleucel (liso-cel) is a drug candidate for recurrent/refractory non-Hodgkin lymphoma or CLL. Acalabrutinib combined with CAR-T cells can increase the mortality of CD19 + tumor cells and prolong the survival of charged tumor mice. It can be preliminarily argued that the combination of liso-cel and acalabrutinib can enhance the therapeutic effect of CAR-T-cell therapy that has been found in CD19 + B-cell malignancies (106)

\subsection{Midostaurin}

\subsubsection{New Mechanisms}

Midostaurin can induce MCL-1 downregulation, thus enhancing the activity of venetoclax, which inhibited BCL-2, in turn leading to Bim release, causing apoptosis. The presence of continuously active and enhanced spleen tyrosine kinase (SYK) in FLT3-ITDpositive AML, its overexpression affects the transformation of AML and its resistance to FLLT3 inhibitors (107). Also, midostaurin had excellent inhibitory effects on FLT3-ITD cells and was 100 times more potent on FLT3-ITD or FLT3-ITD + TEL-SYK cells than SYK inhibitors. The main driver of SYKinduced cell conversion was STAT5, and midostaurin combined with FLT3/SYK dual inhibitor or SYK alone both have good inhibition of STAT5 (108-110).

Multidrug resistance (MDR) is a common cause of chemotherapy failure, and the overexpression of $A B C$ transporters is probably the cause. Midostaurin has been proved to antagonize ABCB1-mediated MDR, but it cannot reverse ATP-binding cassette subfamily G member 2 (abcg2)mediated MDR. Also, midostaurin directly inhibited the efflux function of $\mathrm{ABCB} 1$ transporter and inhibited the ATPase activity of $\mathrm{ABCB} 1$ transporter in a dose-dependent manner. Midostaurin combined with chemotherapy may improve the therapeutic effect of tumor (111).

In the treatment of NSCC, midostaurin inhibits TBK1, PDPK1, and AURKA at the same time, and the combined 
inhibition of these targets changed PI3K/AKT and cell cycle signaling pathways, which were partially concentrated on PLK1 (112).

\subsubsection{New Indications}

Acquired KIT D816V mutation widely exists in patients with advanced systemic mastocytosis (advSM) and also exists in mast cells and other hematopoietic cell lines. Midostaurin can target mast cell chamber and KIT-D816V-positive AHN but may not be able to overcome high molecular risk mutation (S/A/R gene panel). Compared with midostaurin, avapritinib, another KIT inhibitor, showed better in vitro activity even when midostaurin did not respond (113). In additin, midostaurin showed good activity in NSCC treatment (114).

\subsubsection{Novel Combination Regimens}

Adding midostaurin to standard chemotherapy in AML patients with FLT-3 mutations can significantly prolong the total and event-free survival and improve patient prognosis. Midostaurin combined with BCL-2 inhibitor venetoclax has a good therapeutic effect on FLT3-ITD AML (107).

For kinase inhibitor-sensitive/resistant diseases, SYK and FLT3/SYK dual inhibitors can increase midostaurin growth inhibition on cancer cells, providing a reliable reference for the clinical combination regimen of midostaurin. FLT3-ITDpositive AML with a high allele ratio $(>0.5)$ had a poor prognosis; midostaurin combined with the MDM2 inhibitor NVP-HDM201 provides significant therapeutic effects on the wild-type AML of high allelic FLT3-ITD ratio by targeting P53 and NPM1 (110). Also, for AML without FLT3 mutation, midostaurin showed synergistic inhibition with standard chemotherapy drugs and some targeted drugs (112). At the same time, the combination of midostaurin and PLK1 inhibitor was observed to have significant synergistic inhibitory effect on lung cancer cells (114).

\section{THE CHIRAL SMALL MOLECULAR TARGETED ANTITUMOR DRUGS APPROVED BY THE FDA IN 2018}

There are seven chiral small molecular targeted antitumor drugs approved to its list by the FDA in 2017. Encorafenib (13) is for unresectable or metastatic melanoma patients with BRAF V600E or BRAF V600K mutation and treat metastatic colorectal cancer (mCRC) patients with BRAF V600E mutation (combined with cetuximab). Ivosidenib (14) is for recurrent or refractory AML in human with IDH1 mutation and AML patients aged 75 and over who could not use intensive chemotherapy due to other complications. Duvelisib (15) is for recurrent or refractory chronic lymphocytic leukemia(R/R CLL), small lymphocytic lymphoma (SLL), and recurrent or refractory follicular lymphoma. Talazoparib (16) is for locally advanced or metastatic breast cancer with BRCA mutation (harmful or suspected harmful) and HER2 negative. Lorlatinib (17) is for
ALK-positive metastatic NSCLC. Larotrectinib (18) is for adult and child patients with locally advanced or metastatic solid tumors with NTRK gene fusion. Glasdegib (19) is for untreated AML (combined with low-dose cytarabine).

The active enantiomers of encorafenib, ivosidenib, duvelisib, and lorlatinib are (S)-enantiomers. (S,R)-Enantiomers of talazoparib and larotrectinib are approved to its list by the FDA. The active enantiomer of glasdegib is $(\mathrm{R}, \mathrm{R})$-enantiomer.

\subsection{Encorafenib}

\subsubsection{New Mechanisms}

The generation and activation of RAF dimer will lead to the reactivation of MEK-ERK pathway, which is the reason why colorectal cancer is resistant to BRAF inhibitors. PLX8394, a Paradox breaker BRAF inhibitor, can inhibit the formation of RAF dimer. PLX8394 and encorafenib have higher anticancer efficacy than vemurafenib, and the reactivation degree of MEKERK pathway is lower. The dose-response curves of PLX8394 and encorafenib are similar, but there is no significant difference in the reactivation degree of MEK-ERK pathway $(115,116)$.

\subsubsection{Novel Combination Regimens}

The FDA approved encorafenib combined with cetuximab to treat mCRC with BRAF V600E mutation. The activation of PI3K/AKT pathway is considered to be the mechanism of resistance of $\mathrm{mCRC}$ to BRAF inhibitors. Generally speaking, the addition of $\mathrm{PI} 3 \mathrm{~K}$ inhibitor may indeed improve the prognosis of mCRC patients treated with encorafenib combined with cetuximab, although the incidence of adverse events is higher (117).

The triple regimen of Encorafenib combined with cetuximab plus MEK inhibitor binimetinib showed good tolerance and safety in the treatment of mutant mCRC (115). The therapeutic effects of dabrafenib/trametinib, vemurafenib/ cobimetinib, and encorafenib/binimetinib on BARF mutant mCRC were compared in parallel. The encorafenib/binimetinib joint scheme has the longest OS time and higher security. The adverse event of dabrafenib/trametinib regimen is fever, and that of vemurafenib/cobimetinib regimen is photosensitive reaction. Therefore, encorafenib combined with binimetinib has superior curative effect and tolerance (118). Clinical trials of encorafenib and binimetinib combined immunotherapy for melanoma are in progress, for example, two combined clinical trials of CTLA4 antibody ipilimumab and PD1 antibody pembrolizumab (119).

A total of $60 \%$ of patients with BRAF mutant MBMs had brain metastasis, which seriously affected the treatment effect and prognosis of patients. The treatment of encorafenib combined with binimetinib shows the effect of resisting melanoma brain metastasis, and the specific efficacy and safety need further study. In addition, metastatic melanoma is easily resistant to BRAF inhibitors, and serine synthesis may be the cause of drug resistance (120). Furthermore, antifolate methotrexate can be used as sensitizer for BRAF inhibitors dabrafenib and encorafenib. At the same time, the activation mutation of RAS codon 12 is a prognostic marker of the therapeutic effect of methotrexate combined with BRAF inhibitor (121). 


\subsection{Ivosidenib}

\subsubsection{New Mechanisms}

The mutation of IDH1 and IDH2 can cause excessive production of D-2-hydroxyglutaric acid (2-HG) and impaired cell differentiation. RTK pathway mutation and 2-HG restoration mutation (including isomer transformation and the appearance of mIDH1-S280F) are the mechanisms of ivosidenib secondary drug resistance. Furthermore, 2-HG can enter specific cell types, such as tumor-associated immune cells, which may lead to immunosuppression. The emergence of multiple nondominant mutations at the second site of IDH1 can be used as a basis for the combination of mIDH1 inhibitors and other therapies, which will reduce the probability of ivosidenib resistance (122).

\subsubsection{New Indications}

In the treatment of mIDH1 cholangiocarcinoma without progression after chemotherapy, ivosidenib can significantly prolong the progression-free survival (PFS), prolong OS to 10.8 months, and reduce the risk of disease progression and death by $63 \%$, which provides a reliable basis for ivosidenib to treat $\mathrm{mIDH} 1$ cholangiocarcinoma. Ivosidenib is suitable for the treatment of advanced mIDH1 cholangiocarcinoma (123).

Ivosidenib has a certain potential in the treatment of advanced mIDH1 chondrosarcoma, which was well tolerated, had no dose-limiting toxicity, and almost had no treatmentrelated adverse events of grade $\geq 3$. Biopsy report showed that the content of $2-\mathrm{HG}$ decreased significantly after ivosidenib was used. Ivosidenib has the potential to be a candidate drug for patients with advanced mIDH1 chondrosarcoma without treatment options (124).

\subsubsection{Novel Combination Regimens}

For mIDH1 AML patients with FLT3 and RAS mutations, dual treatment with kinase inhibitors has certain therapeutic potential. The dual pharmacological inhibition of mIDH1 and mIDH2 may alleviate the restoration of 2-HG caused by homotypic transformation. In addition, the combination with nontargeted drugs can also improve the prognosis. Ivosidenib combined with intensive chemotherapy drug enasidenib can enhance induction and consolidate treatment for mIDH1/2 AML. Its safety and tolerance are also within the acceptable range (125).

In the treatment of solid tumors (cholangiocarcinoma, osteosarcoma, etc.), ivosidenib shows good oral exposure, rapid absorption, and long terminal half-life after single administration (average $40-102 \mathrm{~h}$ after single administration). The accumulation of ivosidenib in tumor reached a stable state after 15 days of administration, which was moderate accumulation. The reduction of $2-\mathrm{HG}$ reached $98 \%$, which has reached the health standard. The disease characteristics of patients and the concurrent administration of weak CYP3A4 inhibitor/inducer did not affect the exposure of ivosidenib. Ivosidenib at $500 \mathrm{mg}$ q.d. is an appropriate dose (126). Ivosidenib can be used to treat mIDH1 glioma which showed brain penetrance and decreased 2-HG compared with the control group (127).

\subsection{Duvelisib}

\subsubsection{New Mechanisms}

In the combination of duvelisib with ibrutinib or dexamethasone, the inhibition of phosphorylated (p) Akt at serine 473 was observed within $12 \mathrm{~h}$ after duvelisib application, and the reactivation of $\mathrm{mTOCR} 2$-dependent $\mathrm{pAKT}$ was obvious within $24 \mathrm{~h}$. Combined medication significantly inhibited the activation, prolonged the inhibition time of pAKT, and further inhibited the survival and growth signal mediated by mTORC1/ 2 (128).

Mechanically, duvelisib inhibits $\mathrm{PI} 3 \mathrm{~K}-\delta / \gamma$, and then upregulates the apoptosis-promoting $\mathrm{BH} 3$-only protein, thus initiating the apoptosis process of CLL cells. Cell survival is caused by the upregulation of BCL-2. Venetoclax can inhibit BCL-2, thus increasing the degree of apoptosis. At the same time, Duvelisib can reduce MCL-1 mRNA and expressed protein to a small extent, because MCL-1 can promote the survival of malignant lymphoma cells, which may increase the sensitivity of CLL cells to venetoclax[134.

\subsubsection{New Indications}

Duvelisib is superior to ofatumumab in efficacy and safety in the treatment of R/R CLL/SLL and can improve the PFS of patients (129).

\subsubsection{Novel Combination Regimens}

Through high-throughput collaborative screening (128), it was found that the combination of duvelisib and several drugs has significant activity in vivo and in vitro, especially in the treatment of duvelisib combined with ibrutinib or dexamethasone.

The treatment of duvelisib combined with venetoclax can cause more apoptosis of CLL (130). An Ib/II study discussed the efficacy and safety of duvelisib combined with fludarabine, cyclophosphamide, and rituximab (FCR) in the treatment of young patients with CLL. The second-stage dose was determined to be $25 \mathrm{mg}$ b.i.d. About 2/3 of patients reached BM-uMRD. However, $73 \%$ of patients' 3 -year PFS did not show significant advantages compared with FCR triple therapy. At the same time, duvelisib combined with FCR can cause common immunemediated toxicity and infection complications, which can be controlled by intervention (131).

\subsection{Talazoparib}

\subsubsection{New Mechanisms}

Temozolomide resistance often occurs in patients with glioblastoma. The mechanism of DNA repair is considered one of the possible reasons for poor temozolomide resistance. Mechanically, talazoparib enhances temozolomide by inhibiting BER-mediated repair of $\mathrm{N} 3 \mathrm{MeA}$ and N7MeG DNA damage. PARP trapping produces protein-DNA complex in BER intermediate, which causes cytotoxicity and leads to apoptosis. The results of cell experiments in vitro further confirm this theory. Furthermore, talazorib had a significant tendency of multidrug resistance protein 1 (MDR 1) efflux, which probably caused talazorib to pass through the blood-brain barrier only in a small amount (132). This provides an explanation for the loss of 
TMZ sensitization mediated by talazoparib in GBM xenograft model.

There will also be resistance to radiotherapy in GBM treatment, which is directly related to the powerful DNA repair ability of glioblastoma stem cells (GSCs). Compared with photon irradiation combined with TMZ, talazoparib significantly reduced the active number of CSC in GBM cell lines and can obviously prolong G2/M phase tissues and inhibit cell proliferation (133).

A new functional IncRNA was discovered, which was named POLO oxykinase 4-related IncRNA (IncRNA PLK4). In the tissues and cells of hepatocellular carcinoma (HCC), the content of IncRNA RLK4 was significantly downregulated, while talazoparib could increase its expression. Furthermore, talazoparib could enhance the inactivation of YES-related protein (YAP) and cell aging by upregulating the content of IncRNA PLK4, thus achieving the purpose of inhibiting the survival and growth of hepatoma cells (134).

\subsubsection{New Indications}

In the treatment of solid tumors, there was no clinical-related change in PR, QRS, QTcF, or RR interval, heart rate, or ECG morphology after treatment with talazoparib at $1 \mathrm{mg}$ daily (135). Talazoparib has the potential to be an adjuvant therapy for breast cancer patients with gBRCA positive before operation. The patients took talazoparib orally every day before operation for 6 months without taking other chemotherapy methods, and the proportion of patients with RCB-0 (complete pathological remission) increased significantly, and the safety and tolerance were within the controllable range (136).

In vitro studies showed that talazoparib is the substrate of $\mathrm{P}$ glycoprotein and breast cancer drug-resistant protein transporter. Itraconazole (P-glycoprotein inhibitor) increased the plasma exposure of talazobarib, and when P-glycoprotein inhibitor must be combined, the dosage of talazobarib should be appropriately reduced (from $1 \mathrm{mg}$ to $0.75 \mathrm{mg} /$ day). Rifampicin also caused a similar increase in exposure to talazoparib, which indicated that P-glycoprotein inducer had limited effect on talazoparib (137). In the meantime, the treatment of talazoparib combined with these two drugs has good tolerance and safety.

\subsubsection{Novel Combination Regimens}

Talazoparib that inhibits DNA repair have the potential to become a means to solve temozolomide drug resistance (132). In addition to GBM radiotherapy, talazoparib can increase the sensitivity of SCLC to radiotherapy, which can effectively inhibit the sensitivity of SCLC cell line and xenograft model to radiotherapy, and high PARP trapping activity can improve the sensitivity of SCLC to radiotherapy (136). Also, talazoparib can make melanoma cells sensitive to radiotherapy, while healthy tissue cells are less affected, indicating that combined therapy has certain selectivity. Because the research shows great heterogeneity, it is best to detect tumor cells before using this therapy (138).

The combination of PARP inhibitor and APE1 inhibitor may be a candidate treatment for malignant hematological tumors, such as myelodysplastic syndromes/chronic myelomonocytic leukemia and acute myeloid leukemia. Also, talazoparib and APE inhibitor III shows remarkable antileukemia effect, meanwhile, low dose of talazoparib and APE inhibitor can enhance the cytotoxicity of decitabine inmyelodysplastic syndromes/chronic myelomonocytic leukemia and acute myeloid leukemia (139).

\subsection{Lorlatinib}

\subsubsection{New Mechanisms}

Mechanically, both lorlatinib and crizotinib can inhibit endothelial cells, but lorlatinib is more obvious for hcmec/D3 (normalized human brain microvascular endothelial cells). In SH-SY5Y (human neurobionoma cells) hypoxia model, lorlatinib also showed better protection against injured nerve cells than crizotinib. In addition, lorlatinib can downregulate the expression of SPP1, VEGF, TGF- $\beta$, and claudin in brain tissue and upregulate the expression of early growth transcription factor (Egr1), which may lead to the decrease of tight junctions between BBB cells, thus increasing the permeability of bloodbrain barrier, which leads to higher brain exposure of lorlatinib. At the same time, the protective effect of lorlatinib on nerve cells and its characteristic of not affecting the quantity of Pglycoprotein may be the reason why the central nervous system is less resistant to it (140).

Patients of ALK rearrangement lung cancer shows drug resistance to lorlatinib; these mechanisms include epitheilialmesogenic transition susceptible to combined ALK/Src inhibition, ALK compound mutations, and a novel bypass mechanism, mediated by Nf2 loss and outcome by mtor inhibition (141). Continuous use of ALK inhibitors in prophase treatment is likely to promote the occurrence of ALK-compliant mutations. Lorlatinib, the third-generation ALK inhibitor, might avoid refractory ALK mutation in early treatment and optimize clinical treatment effect. Also, the highly targeted inhibition of lorlatinib may cause ALK-independent drug resistance, and this drug resistance mechanism is difficult to overcome once established (142).

\subsubsection{New Indications}

Lorlatinib has the potential to treat ALK/ROS-positive NSCLCinhibiting drug-resistant mutation, which has a good therapeutic effect on patients who have received more than two TKI treatments and failed to be treated, and its safety is in a controllable range (141). A patient with ALK-positive central nervous system disease was successfully treated with lorlatinib for central nervous system metastasis (142). The patient had previously used a large dose of brigatinib.

Lorlatinib is often more effective for patients who fail to be treated well using the second-generation ALK-TKI, and it is very important to further study the plasma and tissue genotyping of ALK mutations and make a prospective prediction of ALK-TKI types for ALK resistance mutations of patients, which is very important for ALK TKI selection of advanced ALK-positive NSCLC patients $(143,144)$.

In the treatment of advanced ALK/ROS-positive NSCLC patients with drug-resistant mutations, lorlatinib, as a 
sequential drug in the treatment of brigatinib and alectinib, can significantly exert its therapeutic activity, and patients have good tolerance to lorlatinib without serious adverse reactions (145). Crizotinib and entrectinib have been approved for the treatment of advanced ROS1 rearrangement lung cancer, and lorlatinib has shown good activity in crizotinib-resistant environment. When the drug resistance of crizotinib and entrectinib is ROS1-G2032R mutation mediated by nontargeted drug resistance, lorlatinib can be used as the second-line treatment for ROS1-rearranged lung cancer, which can appropriately prolong the progression-free survival time of patients (146).

\subsubsection{Novel Combination Regimens}

Compared with crizotinib, lorlatinib is intended for first-line treatment, and the best solution is to use lorlatinib as a combination drug to avoid ALK-dependent and ALKindependent drug resistance (147).

\subsection{Larotrectinib}

\subsubsection{New Mechanisms}

The chimeric protein encoded by NTRK after rearrangement has carcinogenic effect, and at the same time drives constitutive expression and ligand-independent activation. Larotrectinib has a wide range of anti-NTRK fusion cancer effects, regardless of cancer type, age, and fusion partner (148). It is necessary to add NTRK status to the diagnosis workflow of tumor types, which means that some patients will benefit from targeted therapy.

\subsubsection{New Indications}

Larotrectinib is used in children with locally advanced TRK fusion sarcoma, which can help the subsequent surgical resection of sarcoma, which is expected to be a preoperative drug for children with newly diagnosed TRK fusion sarcoma (149). When larotrectinib is used in infants, children, and adolescents, the recommended second-stage dose is $100 \mathrm{mg} / \mathrm{m}^{2}$, which has nothing to do with the age of patients. Also, high response rate and good tolerance have been observed (150). Patients with advanced childhood cancer should be screened for TRK fusion, so as to determine whether larotrectinib can be used for preoperative treatment. Safety data confirmed the feasibility of long-term use of larotrectinib (151).

Rare patients with cervical sarcoma will become the beneficiary group of targeted therapy (152). Larotrectinib also shows certain therapeutic activity in the treatment of infant glioblastoma driven by NTRK, but there is a lack of long-term clinical research data of larotrectinib and this group. At the same time, small molecule targeted therapy may interact with radiotherapy. Therefore, the efficacy and safety of larotrectinib in the treatment of infant glioblastoma need to be further studied (153).

In addition, a clinical study of a Ph-like ALL case presents two genome mutations, one NRASGly12Asp mutation and one ETV6NTRK3 rearrangement, which activate signal transduction. This case is resistant to many chemotherapies and immunotherapies and cannot avoid the recurrence after treatment (154). Researchers speculate that larotrectinib may be used in the early stage of the disease to achieve better curative effect.

\subsection{Glasdegib}

\subsubsection{New Indications}

In the treatment of primary/secondary MF treated with at least one JAKI, glasdegib was safe and tolerant when used alone. Also, the study confirmed that glasdegib has a long-term sustained treatment response to MF (155).

\subsubsection{Novel Combination Regimens}

The therapeutic effect and controllable safety of glasdegib combined with cytarabine have been proved on newly diagnosed AML patients (156). It is preliminarily determined that patients with moderate or severe renal damage may not need to reduce the initial dose of glasdegib (157).

Glasdegib combined with cytarabine showed better therapeutic effect than cytarabine alone. Glasdegib showed population-related adverse events, such as hematological events, gastrointestinal toxicity and fatigue, and adverse events related to hedgehog inhibitors (hair loss, muscle spasm, dysosmia, etc). The above adverse events are within the controllable range. Glasdegib is suitable for long-term treatment (158). Also, glasdegib combined with low-dose cytarabine significantly prolonged the OS of patients, and the therapeutic effect of this combination therapy was more prominent in patients with secondary AML. The third-stage clinical development of glasdegib for $7+3$ intensive chemotherapy is underway (159).

In AML patients who could not receive chemotherapy or patients with high-risk myelodysplastic syndrome, the combined regimen of glasdegib and cytarabine is therapeutic. However, there were 12 gene mutation states which had no obvious correlation with clinical reaction. This shows that the relationship between gene mutation and response or nonresponse to treatment may not be significant, which should be further studied (160). In addition, glasdegib combined with JAKI has certain potential for MF treatment (155).

\section{THE CHIRAL SMALL MOLECULAR TARGETED ANTITUMOR DRUGS APPROVED BY THE FDA IN 2019}

Zanubrutinib (20), darolutamide (21), and alpelisib (22) were approved to its list by the FDA in 2019. Zanubrutinib is for adult mantle cell lymphoma (R/R MCL) patients who had received at least one treatment before. Darolutamide is for nonmetastatic castration-resistant prostate cancer (NM-CRPC). Alpelisib combined with fulvestrant is for the treatment of advanced metastatic breast cancer with hormone receptor positive (HR + )/human epidermal growth factor receptor 2 negative (HER2-) and PIK3CA mutation in male and postmenopausal women. The active enantiomers of the three drugs are (S)-enantiomers.

\subsection{Zanubrutinib}

\subsubsection{New Mechanisms}

Zanubrutinib and ibrutinib share the same binding site as ibrutinib in BTK-cysteine 481 in the adenine triple-binding 
pocket of BTK, which means that with the further extension of follow-up, C481S mutant cells may be reported (161).

Ibrutinib and zanubrutinib can show different inhibitions of action in the stages of virus entry and replication, and have the potential to become new candidate drugs for inhibiting the onset of COVID-19 (162).

\subsubsection{New Indications}

In the treatment of Waldenstrom macroglobulinemia, the incidence and severity of BTK-related toxic events after aanubrutinib treatment were lower than those of ibrutinib. In addition, the two both showed good curative effect, and the difference was not statistically significant (163). Waldenstrom macroglobulinemia has a rare complication-Bing-Neel syndrome, which is often manifested as clonal lymphoplasmacyte infiltration in the central nervous system, in which zanubrutinib has a good effect (164).

Ibrutinib and zanubrutinib showed similar inhibitory effects on MCL cell line Rec-1. Meanwhile, the inhibitory effect of zanubrutinib on ITK is 20 times lower than that of ibrutinib, and it takes 10-45 times of zanubrutinib to achieve the same inhibitory effect on PLC $\gamma 1$ or IL-2 secretion as ibrutinib. The two are equally effective and more selective in vitro. In addition, ibrutinib showed a more significant inhibitory effect on NK cells than zanubrutinib (165). In the treatment of patients with $R / R$ MCL, zanubrutinib achieved a high response rate of $84 \%$ in patients, and PFS was significantly prolonged. Meanwhile, good tolerance and safety were observed. Also, zanubrutinib has monotherapy activity on activated B-cell (ABC)-diffused large B-cell lymphoma cell line (161).

At the same time, BTK inhibitors can improve the symptoms of dyspnea, hypoxia, and thromboinflammation in patients with COVID-19, and the specific mechanism is still under further study (162).

\subsubsection{Novel Combination Regimens}

In addition, zanubrutinib showed synergistic effect on all cell lines with MEK inhibitor pimasertib and BCL2 inhibitor venetoclax in ibrutinib-sensitive model (166). Zanubrutinib and BET bromide inhibitor birabresib are synergistic in three cell lines and additive in two cell lines, while XPO1 antagonist selinexor is beneficial in four cell lines (synergistic in three cell lines and additive in one) (167).

Eighty-one patients with CLL/SLL or R/R follicular lymphoma (FL) showed good overall tolerance and low incidence of adverse reactions after using the regimen of zanubrutinib and obinuzumab. The controlled trial of sample enlargement is in progress (168).

\subsection{Darolutamide}

\subsubsection{New Mechanisms}

The results of transactivation experiments showed that darolutamide and its two optical isomers and major metabolite-keto-darolutamide showed strong competitive antagonism against $\mathrm{AR}$ wild type, which have differences in inhibiting AR activity in prostate cancer VCaP, LAPC-4, and LN $\mathrm{CaP}$ cell lines. In addition, darolutamide and its enantiomers and metabolites on AR dimerization have inhibitory activities in prostate cancer AR wild type, AR W742C mutant, and AR W742L mutant cell lines (169).

After intravenous or oral administration, the level of $(S, S)$ darolutamide was higher than that of $(\mathrm{S}, \mathrm{R})$-darolutamide, and it was also observed that $(\mathrm{S}, \mathrm{R})$-darolutamide changed to $(\mathrm{S}, \mathrm{S})$ darolumide. The diastereomer is similar to keto-darolutamide in pharmacology in vitro. In addition, due to the high protein binding characteristics of keto-darolutamide, its contribution in human body is low (170).

The functional gain mutation of $\mathrm{AR}$ is one of the main reasons for the resistance of PCa to AR antagonists. In $68 \mathrm{AR}$ mutants, darolutamide showed a complete inhibitory effect on AR mutants in 67, even if the concentration of AR mutants increased, there was no partial activation. Bicalutamide led to partial or complete activation to $63 \%$ mutants, and eight mutants were completely or partially activated by enzalutamide (171). The research preliminarily confirmed the broad-spectrum inhibitory effect of darolutamide on AR and its mutants.

Mechanically, darolutamide could block the whole genome AR enhancer, super-enhancer activation, and downstream transcription. In addition, a dynamic AR cistron dependent on androgen level was found, which exists in the high AR affinity region of prostate cancer cell lines and tissue samples. Darolutamide causes the binding of AR to genome to be greatly reduced, which strongly inhibits the activation of normal enhancer and super-enhancers, and then hinders several downstream pathways which are very important for prostate cancer proliferation. In addition, carcinogenic superenhancers is easily affected by the defects of cellular DNA repair mechanism, which provides a theoretical basis for the effective antitumor effect of endocrine therapy combined with DNA damage repair drugs. Related clinical research is underway (172).

Interleukin-23(IL-23) can significantly inhibit the cell aging induced by enzalutamide or darolutamide in castration-resistant C4-2, and 22Rv1 cells, but not in androgen-sensitive LNCaP cells. This indicates that castration-resistant PCa cells have specific reaction to IL-23 which may be one of the causes of resistance to AR antagonists. Developing targeted drugs for IL-23 may be an effective way to improve the efficacy of AR antagonists. The specific reasons for the different expression of IL-23 in above three cells are still under further study (173).

In addition, the overexpression of AKR1C3 is the key regulator of drug resistance of castration-resistant $\mathrm{PCa}$ to apalutamide and darolutamide. KV-49g can significantly inhibit AKR1C3 and greatly improve the drug resistance of cancer cells to these two drugs. Therefore, AKR1C3 is a new potential target, and $\mathrm{KV}-49 \mathrm{~g}$ is an emerging lead compound, which is currently used for preclinical evaluation (174).

\subsubsection{New Indications}

In the nonstatistical casting-resistant prostate cancer of Japan, the efficacy and safety of darolutamide has been proved. However, it is impossible to determine whether there is a safety difference between the Japanese population and the general ARAMIS population (175).

Comparing the efficacy and safety of darolutamide, apalutamide, and enzalutamide, the three drugs can obtain the median 
metabolism-free survival prolongation effect superior to placebo compared with placebo, among which apalutamide has the best effect, followed by enzalutamide and darolutamide. In prostatespecific antigen progression-free survival (PSA-PFS), the performance of three drugs is the same as the median metabolism-free survival. Darolutamide has the lowest incidence of adverse events and the most controllable tolerance (176).

\subsubsection{Novel Combination Regimens}

The combination regimens of darolutamide and other drugs provide almost no DDI, but possibly exert influence on metabolic enzymes or transporters. In addition, the inhibition of darolutamide and rosuvastatin on intestinal efflux transporters was observed, but which did not show significant impact on safety. There is little interaction between darolutamide and other compounds at therapeutic concentration, so the increased exposure of intestinal efflux transporter substrates and possible hepatic uptake transporter substrate may be the main interaction (174). The low potential DDI of darolutamide ensures less complications in the treatment of nonmetastatic castrationresistant prostate cancer.

\subsection{Alpelisib}

\subsubsection{New Mechanisms}

Tamoxifen is the first-line hormone therapy drug for premenopausal women with estrogen receptor (ER)-positive metastatic breast cancer, and the activation of PI3K/AKT pathway will lead to resistance. Alpelisib or buparlisib and tamoxifen have synergistic effects in treating ER-positive breast cancer cell lines with different PI3K mutations. In vitro, significant tumor shrinkage was observed, and their synergistic effect depended on PIK3CA, AKT, and wild-type ER. Potentially, ER and PI3K/AKT pathways are similar to a bidirectional circuit, and the circuit is a standby mechanism for each other (177).

Alpelisib can inhibit the phosphorylation of AKT, mTOR, and ribosomal protein S6, while rapamycin can activate the phosphorylation of AKT (178). When the two are combined, this effect is reversed, and the overall expression is the inhibition of AKT phosphorylation, thus inhibiting the growth of tumor cells (179).

\subsubsection{New Indications}

In the treatment of lipoma associated with PIK3CA-related overgrowth syndrome, alpelisib has shown good therapeutic effect (179).

\subsubsection{Novel Combination Regimens}

PI3K inhibitor and tamoxifen have synergistic effect, which can also delay the occurrence of drug resistance to any single treatment (177). Alpelisib can show good antitumor activity in vitro and in vivo when used alone or in combination with paclitaxel. Meanwhile, alpelisib with paclitaxel can significantly inhibit the migration of cancer cells. The combination of these two drugs has the value of further clinical research (180).

The combination therapy of alpelisib and olaparib had good efficacy and safety in patients with epigenetic ovarian cancer, and the maximum tolerable dose was determined to be $200 \mathrm{mg}$ q.d. and
$200 \mathrm{mg}$ b.i.d. Preliminarily, alpelisib combined with olaparib showed significant synergistic effect in ovarian cancer to platinum resistance to gBRCAwt and BRCAwt. This combination scheme superior to monotherapy has research value (181).

In nonkeratinizing nasopharyngeal carcinoma models, different results were obtained by using ribocilib alone and using ribocilib and alpelisib in combination. Combined medication significantly inhibited tumor growth, and the tumor volume decreased even more (182). In vitro, when alpelisib is used alone or in combination with rapamycin, the reduction of cell proliferation is characterized by concentration and time dependence. Alpelisib alone did not directly kill cells but accelerated cell aging (179).

In colorectal cancer patients with BRAF mutation, double therapy (encorafenib $200 \mathrm{mg} /$ day + cetuximab) and triple therapy (encorafenib $200 \mathrm{mg} /$ day + alpelisib $300 \mathrm{mg} /$ day + cetuximab) showed good clinical efficacy and safety. At the same time, it was observed that alpelisib in triple-therapy group had mild DDI with encorafenib at higher dose, that is, the exposure of encorafenib increased by 2 times. This may be because alpelisib inhibited CYP3A4, the metabolic enzyme of encorafenib. Cetuximab and encorafenib did not affect the exposure of alpelisib (117).

\section{DISCUSSION}

The introduction of the concept of chirality provides new ideas for the research of small molecular targeted anticancer drugs. Most of the chiral small molecular targeted drugs approved by the FDA are the single enantiomer, and the enantiomers of these drugs are either inactive, low in activity, or high in activity. Crizotinib in market, for example, has a chiral compound with the $(\mathrm{R})$-configuration, approved by the FDA. Although the (S)configuration is not approved, it targets different enzyme named MTH1, making it certain anticancer activity either. The (R)configuration of ruxolitinib shows higher target binding priority than the $(S)$-configuration because of its stereostructure specificity. Darolutamide and its $(\mathrm{S}, \mathrm{S})$-configuration and $(\mathrm{S}, \mathrm{R})$ configuration as well as its metabolites have AR inhibitory activity in vivo.

In this review, the chiral small molecular targeted drugs approved by the FDA from 2011 to 2019 were systematically summarized, and the new mechanisms, new indications, and novel combination regimens of each drug in recent years were presented. It can be seen that the research on unapproved enantiomers of these drugs is relatively scarce, and researchers pay less attention to explore the chiral characteristics of these drugs, which may be directly related to the difficulty of chiral resolution in certain situations. In fact, the chirality of drug molecules will directly affect its distribution, absorption, metabolism, and excretion in vivo, as well as pharmacodynamics and pharmacotoxicology. A well-designed study of chiral drug molecules can better grasp the metabolism and mechanism of drug molecules in human body (178).

Undeniably, small molecular targeted drugs have certain limitations in the treatment of tumors. Many patients often need genetic testing to determine whether they meet the 
medication requirements. Drug resistance and relatively high treatment cost also become the limitations of further popularization of this treatment method. Clinically, small molecular targeted drugs are often used in combination with other drugs to achieve the purpose of optimizing efficacy, overcoming drug resistance, and improving safety. In addition, it is a pleasure for researchers to actively explore new indications of existing small molecular targeted drugs in order to expand the population of beneficiary patients, and the research results of some drugs have been satisfactory. Talazorib was initially approved by the FDA for the treatment of breast cancer with BRCA gene mutation. Because of its remarkable curative effect, researchers actively carried out research on other indications of this drug, and finally found that talazoparib had unexpected therapeutic effect on triple negative breast cancer, and this indication has been approved by the FDA $(183,184)$.

We have speculated that the reason that talazoparib shows distinctive superiority is probably related to its chirality. As the fourth-generation PARP inhibitor, its efficacy is more than 100 times that of the first-generation PARP inhibitor olaparib (no chirality), which may also be caused by its chiral center. Therefore, in order to effectively solve the current problems in small molecular targeted therapy, the advantage of chiral structure to drugs is a kind of guidance, which will lead us to find a new idea for directing our furture research.

\section{REFERENCES}

1. Kania-Korwel I, Lehmler HJ. Chiral Polychlorinated Biphenyls: Absorption, Metabolism and Excretion-a Review. Env Sci Poll Res (2016) 23:2042-57. doi: 10.1007/s11356-015-4150-2

2. Debasmita S, Kharbanda A, Yan W, Lakkaniga NR, Frett B, Li H-Y. The Exploration of Chirality for Improved Druggability Within the Human Kinome. J Med Chem (2020) 63:441-69. doi: 10.1021/acs.jmedchem.9b00640

3. Ilirjana B, Marlow R, van de Ven M, Brough R, Pemberton HN, Frankum J, et al. E-Cadherin/ROS1 Inhibitor Synthetic Lethality in Breast Cancer. Cancer Discovery (2018) 4:498-515. doi: 10.1158/2159-8290.CD-17-0603

4. Zhou Y, Zhao C, Gery S, Braunstein GD, Okamoto R, Alvarez R, et al. OffTarget Effects of C-MET Inhibitors on Thyroid Cancer Cells. Mol Cancer Ther (2014) 13:134-43. doi: 10.1158/1535-7163.MCT-13-0187

5. Megiorni F, McDowell HP, Camero S, Mannarino O, Ceccarelli S, Paiano M, et al. Crizotinib-Induced Antitumour Activity in Human Alveolar Rhabdomyosarcoma Cells is Not Solely Dependent on ALK and MET Inhibition. J Exp Clin Cancer Res (2015) 34:112. doi: 10.1186/s13046-0150228-4

6. You L, Shou J, Deng D, Jiang L, Jing Z, Yao J, et al. Crizotinib Induces Autophagy Through Inhibition of the STAT3 Pathway in Multiple Lung Cancer Cell Lines. Oncotarget (2015) 37:40268-82. doi: 10.18632/ oncotarget.5592

7. Das I, Chen H, Maddalo G, Tuominen R, Rebecca VW, Herlyn M, et al. Inhibiting Insulin and mTOR Signaling by Afatinib and Crizotinib Combination Fosters Broad Cytotoxic Effects in Cutaneous Malignant Melanoma. Cell Death Dis (2020) 10:882. doi: 10.1038/s41419-020-03097-2

8. Ji J, Chen W, Lian W, Chen R, Yang J, Zhang Q, et al. (S)-Crizotinib Reduces Gastric Cancer Growth Through Oxidative DNA Damage and Triggers ProSurvival Akt Signal. Cell Death Dis (2018) 6:660. doi: 10.1038/s41419-0180667-x

9. Dai X, Guo G, Zou P, Cui R, Chen W, Chen X, et al. (S)-Crizotinib Induces Apoptosis in Human Non-Small Cell Lung Cancer Cells by Activating ROS Independent of MTH1. J Exp Clin Cancer Res (2017) 36:120. doi: 10.1186/ s13046-017-0584-3
In a word, studying the pharmacological activities of drug molecules and their chiral enantiomers can provide extensive data for the clinical application of drugs, help researchers to know the role of chiral centers in drug activity, and provide new evidence and ideas for the joint use of drugs and the discovery of new signal pathways.

\section{AUTHOR CONTRIBUTIONS}

$\mathrm{XC}$ : data curation and writing-original draft preparation. YB: software. XY: writing-reviewing and editing.

\section{FUNDING}

This work was supported by the National Natural Science Foundation of China (No. 81874212, 82172653); Huxiang High-Level Talent Innovation Team (2018RS3072); Opening Fund for Key Laboratory of Molecular Pharmacology and Drug Evaluation (Yantai University), Ministry of Education (P201905); Scientific and Technological Projects for Collaborative Prevention and Control of Birth Defect in Hunan Province (2019SK1012); and Key Grant of Research and Development in Hunan Province (2020DK2002).

10. Kim DW, Ahn MJ, Shi Y, Pas TMD, Shaw AT. Results of a Global Phase II Study With Crizotinib in Advanced ALK-Positive Non-Small Cell Lung Cancer (NSCLC). Ann Oncol (2012) 30:32-3. doi: 10.1016/S0923-7534(20)32006-8

11. Shaw AT, Kim D-W, Nakagawa K, Seto T, Crinó L, Ahn M-J, et al. Crizotinib Versus Chemotherapy in Advanced ALK-Positive Lung Cancer. N Engl J Med (2013) 25:2385-94. doi: 10.1056/NEJMoa1214886

12. Butrynski JE, D'Adamo DR, Hornick JL, Cin PD, Shapiro GI. Crizotinib in ALK-Rearranged Inflammatory Myofibroblastic Tumor. N Engl J Med (2010) 363:1727-33. doi: 10.1056/NEJMoa1007056

13. Mossé YP, Lim MS, Voss SD, Wilner K, Ruffner K, Laliberte J, et al. Safety and Activity of Crizotinib for Paediatric Patients With Refractory Solid Tumours or Anaplastic Large-Cell Lymphoma: A Children's Oncology Group Phase 1 Consortium Study. Lancet Oncol (2013) 6:472-80. doi: 10.1016/S1470-2045(13)70095-0

14. Bresler SC, Wood AC, Haglund EA, Courtright J, Belcastro LT, Plegaria JS, et al. Differential Inhibitor Sensitivity of Anaplastic Lymphoma Kinase Variants Found in Neuroblastoma. Sci Transl Med (2011) 108:108ra114. doi: 10.1126/scitranslmed.3002950

15. Srdan Verstovsek MD, Mesa RA, Gotlib J, Levy RS, Gupta V, Path FRC, et al. A Double-Blind, Placebo-Controlled Trial of Ruxolitinib for Myelofibrosis. N Engl J Med (2012) 9:799-807. doi: 10.1056/NEJMoa1110557

16. Harrison C, Kiladjian JJ, Al-Ali HK, Gisslinger H, Barosi G. JAK Inhibition With Ruxolitinib Versus Best Available Therapy for Myelofibrosis. N Engl J Med (2012) 9:787-98. doi: 10.1056/NEJMoa1110556

17. US Food and Drug Administration. Ruxolitinib. (2011). Available from: http:// www.fda.gov/drugs/informationondrugs/approveddrugs/ucm395386.htm.

18. Albeituni S, Verbist KC, Tedrick PE. Mechanisms of Action of Ruxolitinib in Murine Models of Hemophagocytic Lymphohistiocytosis. Blood (2019) 2:147-59. doi: 10.1182/blood.2019000761

19. Shanavas M, Popat U, Michaelis LC, Fauble V, McLornan D, Klisovic R, et al. Outcomes of Allogeneic Hematopoietic Cell Transplantation in Patients With Myelofibrosis With Prior Exposure to Janus Kinase 1/2 Inhibitors. Biol Blood Marrow Transplant (2016) 3:432-40. doi: 10.1016/j.bbmt.2015.10.005

20. Ahmed A, Merrill SA, Alsawah F, Bockenstedt P, Campagnaro E, Devata S, et al. Ruxolitinib in Adult Patients With Secondary Haemophagocytic 
Lymphohistiocytosis: An Open-Label, Single-Centre, Pilot Trial. Lancet Haematol (2019) 12:e630-7. doi: 10.1016/S2352-3026(19)30156-5

21. La Rosée F, Bremer HC, Gehrke I, Kehr A, Hochhaus A, Birndt S, et al. The Janus Kinase 1/2 Inhibitor Ruxolitinib in COVID-19 With Severe Systemic Hyperinflammation. Leukemia (2020) 34:1799-804. doi: 10.1038/s41375-020-0891-0

22. Cao Y, Wei J, Zou L, Jiang T, Wang G, Chen L, et al. Ruxolitinib in Treatment of Severe Coronavirus Disease 2019 (COVID-19): A Multicenter, Single-Blind, Randomized Controlled Trial. J Allergy Clin Immunol (2020) 146:137-46. doi: 10.1016/j.jaci.2020.05.019

23. Gowin K, Kosiorek H, Dueck A, Mascarenhas J, Hoffman R, Reeder C, et al. Multicenter Phase 2 Study of Combination Therapy With Ruxolitinib and Danazol in Patients With Myelofibrosis. Leukemia Research (2017) 60:31-5. doi: 10.1016/j.leukres.2017.06.005

24. Li Y, Zhu S, Liu W, Ming J, Wang X, Hu X. Ruxolitinib-Based Combinations in the Treatment of Myelofibrosis: Worth Looking Forward to. Ann Hematol (2020) 6:1161-76. doi: 10.1007/s00277-020-04028-z

25. Arastu-Kapur S, Anderl JL, Kraus M, Parlati F, Shenk KD, Lee SJ, et al. NonProteasomal Targets of the Proteasome Inhibitors Bortezomib and Carfilzomib: A Link to Clinical Adverse Events. Clin Cancer Res (2011) 9:2734-43. doi: 10.1158/1078-0432.CCR-10-1950

26. Bruna J, Udina E, Alé A, Vilches JJ, Vynckier A, Monbaliu J, et al. Neurophysiological, Histological and Immunohistochemical Characterization of Bortezomib-Induced Neuropathy in Mice. Exp Neurol (2010) 2:599-608. doi: 10.1016/j.expneurol.2010.02.006

27. Poruchynsky MS, Sackett DL, Robey RW, Ward Y, Annunziata C, Fojo T. Proteasome Inhibitors Increase Tubulin Polymerization and Stabilization in Tissue Culture Cells: A Possible Mechanism Contributing to Peripheral Neuropathy and Cellular Toxicity Following Proteasome Inhibition. Cell Cycle (2008) 7:940-9. doi: 10.4161/cc.7.7.5625

28. Gao M, Chen G, Wang H, Xie B, Hu L, Kong Y, et al. Therapeutic Potential and Functional Interaction of Carfilzomib and Vorinostat in T-Cell Leukemia/ Lymphoma. Oncotarget (2016) 20:29102-15. doi: 10.18632/oncotarget.8667

29. Vangala JR, Potluri A, Radhakrishnan SK. BET Inhibitors Synergize With Carfilzomib to Induce Cell Death in Cancer Cells via Impairing Nrf1 Transcriptional Activity and Exacerbating the Unfolded Protein Response. Biomolecules (2020) 4:501. doi: 10.3390/biom10040501

30. Efentakis P, Kremastiotis G, Varela A, Nikolaou PE, Terpos E. Molecular Mechanisms of Carfilzomib-Induced Cardiotoxicity in Mice and the Emerging Cardioprotective Role of Metformin. Lymphoid Neoplasia (2019) 7:710-23. doi: 10.1182/blood-2018-06-858415

31. Teicher BA, Tomaszewski JE. Proteasome Inhibitors. Biochem Pharmacol (2015) 7:1-9. doi: 10.1016/j.bcp.2015.04.008

32. Vij R, Siegel DS, Jagannath S, Jakubowiak AJ, Stewart AK, McDonagh K, et al. An Open-Label, Single-Arm, Phase 2 Study of Single-Agent Carfilzomib in Patients With Relapsed and/or Refractory Multiple Myeloma Who Have Been Previously Treated With Bortezomib. Br J Haematol (2012) 158:739-48. doi: 10.1111/j.1365-2141.2012.09232.x

33. Kuhn DJ, Hunsucker SA, Chen Q, Voorhees PM, Orlowski M, Orlowski RZ. Targeted Inhibition of the Immunoproteasome Is a Potent Strategy Against Models of Multiple Myeloma That Overcomes Resistance to Conventional Drugs and Nonspecific Proteasome Inhibitors. Blood (2009) 113:4667-76. doi: 10.1182/blood-2008-07-171637

34. Lamothe B, Wierda WG, Keating MJ, Gandhi V. Carfilzomib Triggers Cell Death in Chronic Lymphocytic Leukemia by Inducing Proapoptotic and Endoplasmic Reticulum Stress Responses. Clin Cancer Res (2016) 18:471226. doi: 10.1158/1078-0432.CCR-15-2522

35. Tremblay S, Driscoll JJ, Rike-Shields A, Hildeman DA, Alloway RR, Girnita $\mathrm{AL}$, et al. A Prospective, Iterative, Adaptive Trial of Carfilzomib-Based Desensitization. Am J Transplant (2020) 2:411-21. doi: 10.1111/ajt.15613

36. Landgren O, Sonneveld P, Jakubowiak A, Mohty M, Iskander KS, Mezzi K, et al. Carfilzomib With Immunomodulatory Drugs for the Treatment of Newly Diagnosed Multiple Myeloma. Leukemia (2019) 9:2127-43. doi: 10.1038/s41375-019-0517-6

37. Jeitany M, Prabhu A, Dakle P, Pathak E, Madan V, Kanojia D, et al. Novel Carfilzomib-Based Combinations as Potential Therapeutic Strategies for Liposarcomas. Cell Mol Life Sci (2021) 4:1837-51. doi: 10.1007/s00018-020-03620-w

38. Ho G-F, Chai C-S, Alip A, Wahid MIA, Abdullah MM, Foo Y-C, et al. RealWorld Experience of First-Line Afatinib in Patients With EGFR-Mutant
Advanced NSCLC: A Multicenter Observational Study. BMC Cancer (2019) 19:896. doi: 10.1186/s12885-019-6107-1

39. Hu X, Shi S, Wang H, Yu X, Wang Q, Jiang S, et al. Blocking Autophagy Improves the Anti-Tumor Activity of Afatinib in Lung Adenocarcinoma With Activating EGFR Mutations In Vitro and In Vivo. Sci Rep (2017) 7:4559. doi: 10.1038/s41598-017-04258-8

40. Li B, Yuan Z, Jiang J, Rao Y. Anti-Tumor Activity of Shikonin Against Afatinib Resistant Non-Small Cell Lung Cancer via Negative Regulation of PI3K/Akt Signaling Pathway. Biosci Rep (2018) 6:BSR20181693. doi: 10.1042/BSR20181693

41. Yoshioka T, Shien K, Takeda T, Takahashi Y, Kurihara E, Ogoshi Y, et al. Acquired Resistance Mechanisms to Afatinib in HER2-Amplified Gastric Cancer Cells. Cancer Sci (2019) 8:2549-57. doi: 10.1111/cas.14089

42. Bonazzoli E, Cocco E, Lopez S, Bellone S, Zammataro L, Bianchi A, et al. PI3K Oncogenic Mutations Mediate Resistance to Afatinib In HER2/neu Overexpressing Gynecological Cancers. Gynecol Oncol (2019) 1:158-64. doi: 10.1016/j.ygyno.2019.01.002

43. Vengoji R, Macha MA, Nimmakayala RK, Rachagani S, Siddiqui JA, Mallya $\mathrm{K}$, et al. Afatinib and Temozolomide Combination Inhibits Tumorigenesis by Targeting EGFRvIII-Cmet Signaling in Glioblastoma Cells. J Exp Clin Cancer Res (2019) 38:266. doi: 10.1186/s13046-019-1264-2

44. Spicer J, Irshad S. A Phase I Study of Afatinib Combined With Paclitaxel and Bevacizumab in Patients With Advanced Solid Tumors. Cancer Chemother Pharmacol (2017) 1:17-27. doi: 10.1007/s00280-016-3189-1

45. O’Brien MER, Sarker D, Bhosle J, Thillai K, Yap TA, Uttenreuther-Fischer M, et al. A Phase I Study to Assess Afatinib in Combination With Carboplatin or With Carboplatin Plus Paclitaxel in Patients With Advanced Solid Tumors. Cancer Chemother Pharmacol (2018) 5:757-66. doi: $10.1007 / \mathrm{s} 00280-018-3661-1$

46. De Pauw I, Lardon F, Van den Bossche J, Baysal H, Fransen E, Deschoolmeester V, et al. Simultaneous Targeting of EGFR, HER2, and HER4 by Afatinib Overcomes Intrinsic and Acquired Cetuximab Resistance in Head and Neck Squamous Cell Carcinoma Cell Lines. Mol Oncol (2018) 6:830-54. doi: 10.1002/1878-0261.12197

47. Coutré SE, Furman RR, Flinn IW, Burger JA, Blum K, Sharman J, et al. Extended Treatment With Single-Agent Ibrutinib at the $420 \mathrm{Mg}$ Dose Leads to Durable Responses in Chronic Lymphocytic Leukemia/Small Lymphocytic Lymphoma. Clin Cancer Res (2017) 23(5):1149-55. doi: 10.1158/1078-0432.CCR-16-1431

48. Byrd JC, Furman RR, Coutre SE, Flinn IW, Burger JA, Blum K, et al. Ibrutinib Treatment for First-Line and Relapsed/Refractory Chronic Lymphocytic Leukemia: Final Analysis of the Pivotal Phase Ib/II PCYC1102 Study. Clin Cancer Res (2020) 15:3918-27. doi: 10.1158/10780432.CCR-19-2856

49. Amin NA, Balasubramanian S, Saiya-Cork K, Shedden K, Hu N, Malek SN. Cell-Intrinsic Determinants of Ibrutinib-Induced Apoptosis in Chronic Lymphocytic Leukemia. Clin Cancer Res (2017) 4:1049-59. doi: 10.1158/ 1078-0432.CCR-15-2921

50. Reiff SD, Mantel R, Smith LL, Greene JT, Muhowski EM, Fabian CA, et al. The BTK Inhibitor ARQ 531 Targets Ibrutinib Resistant CLL and Richter's Transformation. Cancer Discovery (2018) 10:1300-15. doi: 10.1158/21598290.CD-17-1409

51. Manna A, Aulakh S, Jani P, Ahmed S, Akhtar S. Targeting CD38 Enhances the Antileukemic Activity of Ibrutinib in Chronic Lymphocytic Leukemia (CLL). Clin Cancer Res (2019) 13:3974-85. doi: 10.1158/1078-0432.CCR-18-3412

52. Amengual JE, Prabhu SA, Lombardo M, Zullo K, Johannet PM, Gonzalez Y, et al. Mechanisms of Acquired Drug Resistance to the HDAC6 Selective Inhibitor Ricolinostat Reveals Rational Drug: Drug Combination With Ibrutinib. Clin Cancer Res (2017) 12:3084-96. doi: 10.1158/10780432.CCR-16-2022

53. Grommes C, Pastore A, Palaskas N, Tang SS, Campos C, Schartz D, et al. Ibrutinib Unmasks Critical Role of Bruton Tyrosine Kinase in Primary CNS Lymphoma. Cancer Discovery (2017) 9:1018-29. doi: 10.1158/21598290.CD-17-0613

54. Zhang H, Patel A, Wang Y-J, Zhang Y-K, Kathawala RJ, Qiu L-H, et al. The BTK Inhibitor Ibrutinib (PCI-32765) Overcomes Paclitaxel Resistance in $\mathrm{ABCB} 1$ - and $\mathrm{ABCC} 10-$ Overexpressing Cells and Tumors. Mol Cancer Ther (2017) 16(6):1021-30. doi: 10.1158/1535-7163.MCT-16-0511 
55. Lin C-H, Elkholy KH, Wani NA, Li D, Hu P, Barajas JM, et al. Ibrutinib Potentiates Anti-Hepatocarcinogenic Efficacy of Sorafenib by Targeting EGFR in Tumor Cells and BTK in Immune Cells in the Stroma. Mol Cancer Ther (2020) 2:384-96. doi: 10.1158/1535-7163.MCT-19-0135

56. Martinelli S, Maffei R, Fiorcari S, Quadrelli C, Zucchini P, Benatti S, et al. Idelalisib Impairs T-Cell-Mediated Immunity in Chronic Lymphocytic Leukemia. Haematologica (2018) 12:e598-601. doi: 10.3324/ haematol.2017.187070

57. Alflen A, Stadler N, Aranda Lopez P, Teschner D, Theobald M, Heß G, et al. Idelalisib Impairs TREM-1 Mediated Neutrophil Inflammatory Responses. Sci Rep (2018) 8:5558. doi: 10.1038/s41598-018-23808-2

58. Modi P, Balakrishnan K, Yang Q, Wierda WG, Keating MJ, Gandhi V. Idelalisib and Bendamustine Combination Is Synergistic and Increases DNA Damage Response in Chronic Lymphocytic Leukemia Cells. Oncotarget (2017) 8(10):16259-74. doi: 10.18632/oncotarget.15180

59. Yang S, Zhu Z, Zhang X, Zhang N, Yao Z. Idelalisib Induces PUMADependent Apoptosis in Colon Cancer Cells. Oncotarget (2017) 4:6102-13. doi: 10.18632/oncotarget.14043

60. Yue D, Sun X. Idelalisib Promotes Bim-Dependent Apoptosis Through AKT/FoxO3a in Hepatocellular Carcinoma. Cell Death Dis (2018) 10:935. doi: 10.1038/s41419-018-0960-8

61. Barrachina MaríaN, Izquierdo I, Hermida-Nogueira L, Morán LA, Pérez A, Arroyo AB, et al. The PI3K $\delta$ Inhibitor Idelalisib Diminishes Platelet Function and Shows Antithrombotic Potential. Int J Mol Sci (2021) 22 (7):3304. doi: 10.3390/ijms22073304

62. Zelenetz AD, Barrientos JC, Brown JR, Coiffier B, Delgado J, Egyed M, et al. Idelalisib or Placebo in Combination With Bendamustine and Rituximab in Patients With Relapsed/Refractory CLL - Interim Results of a Phase 3 Randomized, Double-Blind Placebo-Controlled Trial. Lancet Oncol (2017) 3:297-311. doi: 10.1016/S1470-2045(16)30671-4

63. Smith SM, Pitcher BN, Jung S-H, Bartlett NL, Wagner-Johnston N, Park SI, et al. Safety and Tolerability of Idelalisib, Lenalidomide, and Rituximab in Relapsed and Refractory Lymphoma: Alliance A051201 and A051202 Phase I Trials. Lancet Haematol (2017) 4:e176-82. doi: 10.1016/S2352-3026(17) 30028-5

64. Palazzo A, Herter S, Grosmaire L, Jones R, Frey CR, Limani F, et al. The Pi3k $\delta$-Selective Inhibitor Idelalisib Minimally Interferes With Immune Effector Function Mediated by Rituximab or Obinutuzumab and Significantly Augments B Cell Depletion In Vivo. J Immunol (2018) 7:2304-12. doi: 10.1016/S2352-3026(17)30028-5

65. Yang Y, Lei H, Qiang Y-w, Wang B. Ixazomib Enhances Parathyroid Hormone-Induced $\beta$-Catenin/T-Cell Factor Signaling by Dissociating $\beta$ Catenin From the Parathyroid Hormone Receptor. Mol Biol Cell (2017) 13:1792-803. doi: 10.1091/mbc.E17-02-0096

66. Yuea D, Sunb X. Ixazomib Promotes CHOP-Dependent DR5 Induction and Apoptosis in Colorectal Cancer Cells. Cancer Biol Ther (2019) 3:284-94. doi: 10.1080/15384047.2018.1529095

67. Advani AS, Cooper B, Visconte V, Elson P, Chan R, Carew J, et al. A Phase 1/ 2 Trial of MEC (Mitoxantrone, Etoposide, Cytarabine) in Combination With Ixazomib for Relapsed Refractory Acute Myeloid Leukemia. Clin Cancer Res (2019) 25(14):4231-7. doi: 10.1158/1078-0432.CCR-18-3886

68. Hou J, Jin J, Xu Y, Wu D, Ke X, Zhou D, et al. Randomized, Double-Blind, Placebo-Controlled Phase III Study of Ixazomib Plus LenalidomideDexamethasone in Patients With Relapsed/Refractory Multiple Myeloma: China Continuation Study. J Hematol Oncol (2017) 10:137. doi: 10.1186/ s13045-017-0501-4

69. Gupta N, Yang H, Hanley MJ, Zhang S, Liu R, Kumar S, et al. Dose and Schedule Selection of the Oral Proteasome Inhibitor Ixazomib in Relapsed/ Refractory Multiple Myeloma: Clinical and Model-Based Analyses. Target Oncol (2017) 5:643-54. doi: 10.1007/s11523-017-0524-3

70. Kumar SK, Berdeja JG, Niesvizky R, Lonial S, Laubach JP, Hamadani M, et al. Ixazomib, Lenalidomide, and Dexamethasone in Patients With Newly Diagnosed Multiple Myeloma: Long-Term Follow-Up Including Ixazomib Maintenance. Leukemia (2019) 7:1736-46. doi: 10.1038/s41375-019-0384-1

71. San-Miguel JF, Echeveste Gutierrez M-A, Špicka I, Mateos M-V, Song K, Craig MD, et al. A Phase I/II Dose-Escalation Study Investigating All-Oral Ixazomib-Melphalan-Prednisone Induction Followed by Single-Agent Ixazomib Maintenance in Transplant-Ineligible Newly Diagnosed Multiple
Myeloma. Haematologica (2018) 9:1518-26. doi: 10.3324/ haematol.2017.185991

72. Castillo JJ, Meid K, Flynn CA, Chen J, Demos MG, Guerrera ML, et al. Ixazomib, Dexamethasone, and Rituximab in Treatment-Naive Patients With Waldenström Macroglobulinemia: Long-Term Follow-Up. Blood Adv (2020) 16:3952-9. doi: 10.1182/bloodadvances.2020001963

73. Gupta N, Hanley MJ, Venkatakrishnan K, Bessudo A, Rasco DW, Sharma S, et al. Effects of Strong CYP3A Inhibition and Induction on the Pharmacokinetics of Ixazomib, an Oral Proteasome Inhibitor: Results of Drug-Drug Interaction Studies in Patients With Advanced Solid Tumors or Lymphoma and a Physiologically Based Pharmacokinetic Analysis. J Clin Pharmacol (2018) 2:180-92. doi: 10.1002/jcph.988

74. Rinnerthaler G, Gampenrieder SP, Petzer A, Burgstaller S, Fuchs D, Rossmann D, et al. Ixazomib in Combination With Carboplatin in Pretreated Women With Advanced Triple-Negative Breast Cancer, a Phase I/II Trial of the AGMT (AGMT MBC-10 Trial). BMC Cancer (2018) 18:1074. doi: 10.1186/s12885-018-4979-0

75. Kumari A, Yokota Y, Li L, Bradley RM, Mistretta CM. Species Generalization and Differences in Hedgehog Pathway Regulation of Fungiform and Circumvallate Papilla Taste Function and Somatosensation Demonstrated With Sonidegib. Sci Rep (2018) 8:16150. doi: 10.1038/s41598-018-34399-3

76. Ross AE, Hughes RM, Glavaris S, Ghabili K, He P, Anders NM, et al. Pharmacodynamic and Pharmacokinetic Neoadjuvant Study of Hedgehog Pathway Inhibitor Sonidegib (LDE-225) in Men With High-Risk Localized Prostate Cancer Undergoing Prostatectomy. Oncotarget (2017) 61:10418292. doi: $10.18632 /$ oncotarget.22115

77. DeFilipp Z, Nazarian RM, El-Jawahri A, Li S, Brown J, Del Rio C, et al. Phase 1 Study of the Hedgehog Pathway Inhibitor Sonidegib for Steroid-Refractory Chronic Graft-Versus-Host Disease. Blood Adv (2017) 22:1919-22. doi: 10.1182/bloodadvances.2017011239

78. Villani A, Fabbrocini G, Costa C, Scalvenzi M. Sonidegib: Safety and Efficacy in Treatment of Advanced Basal Cell Carcinoma. Dermatol Ther (Heidelb) (2020) 3:401-12. doi: 10.1007/s13555-020-00378-8

79. Gupta V, Wolleschak D, Hasselbalch H, Vannucchi AM, Koschmieder S, Cervantes F, et al. Safety and Efficacy of the Combination of Sonidegib and Ruxolitinib in Myelofibrosis: A Phase 1b/2 Dose-Finding Study. Blood Adv (2020) 13:3063-71. doi: 10.1182/bloodadvances.2019001212

80. Ribas A, Daud A, Pavlick AC, Gonzalez R, Lewis KD, Hamid O, et al. Extended 5-Year Follow-Up Results of a Phase 1b Study (BRIM7) of Vemurafenib and Cobimetinib in BRAF-Mutant Melanoma. Clin Cancer Res (2020) 1:46-53. doi: 10.1158/1078-0432.CCR-18-4180

81. Asfuroğlu M, Asfuroğlu Y. A Novel Side Effect of Mitogen-Activated Protein Kinase Inhibitor Cobimetinib: Acute Corneal Decompensation. Indian J Ophthalmol (2019) 12:2073-5. doi: 10.4103/ijo.IJO_2025_18

82. King AC, Diamond EL, Orozco JS, Morse HR, Ouyang LL, Schöder H, et al. Cobimetinib-Induced "Dropped Head Syndrome" and Subsequent Disease Management in an Erdheim-Chester Patient. Clin Case Rep (2019) 10:198993. doi: $10.1002 / \mathrm{ccr} 3.2297$

83. Han L, Zhang Q, Dail M, Shi C, Cavazos A, Ruvolo VR, et al. Concomitant Targeting of BCL2 With Venetoclax and MAPK Signaling With Cobimetinib in Acute Myeloid Leukemia Models. Haematologica (2020) 105(3):697-707. doi: 10.3324/haematol.2018.205534

84. Kawakami H, Huang S, Pal K, Dutta SK, Mukhopadhyay D, Sinicrope FA. Mutant BRAF Upregulates MCL-1 to Confer Apoptosis Resistance That Is Reversed by MCL-1 Antagonism and Cobimetinib in Colorectal Cancer. Mol Cancer Ther (2016) 15(12):3015-27. doi: 10.1158/1535-7163.MCT-16-0017

85. Seipel K, Marques MAT, Sidler C, Mueller BU, Pabst T. The Cellular P53 Inhibitor MDM2 and the Growth Factor Receptor FLT3 as Biomarkers for Treatment Responses to the MDM2-Inhibitor Idasanutlin and the MEK1 Inhibitor Cobimetinib in Acute Myeloid Leukemia. Cancers (Basel) (2018) 6:170. doi: 10.3390/cancers 10060170

86. Daud A, Gill J, Kamra S, Chen L, Ahuja A. Indirect Treatment Comparison of Dabrafenib Plus Trametinib Versus Vemurafenib Plus Cobimetinib in Previously Untreated Metastatic Melanoma Patients. J Hematol Oncol (2017) 10:3. doi: 10.1186/s13045-016-0369-8

87. Hellmann MD, Kim T-W, Lee CB, Goh B-C, Miller WH Jr, Oh D-Y, et al. Phase Ib Study of Atezolizumab Combined With Cobimetinib in Patients 
With Solid Tumors. Ann Oncol (2019) 7:1134-42. doi: 10.1093/annonc/ mdz113

88. Lieu CH, Hidalgo M, Berlin JD, Ko AH, Cervantes A, LoRusso P, et al. A Phase Ib Dose-Escalation Study of the Safety, Tolerability, and Pharmacokinetics of Cobimetinib and Duligotuzumab in Patients With Previously Treated Locally Advanced or Metastatic Cancers With Mutant KRAS. Oncologist (2017) 9:1024-e89. doi: 10.1634/theoncologist.2017-0175

89. van Andel L, Rosing H, Zhang Z, Hughes L, Kansra V, Sanghvi M, et al. Determination of the Absolute Oral Bioavailability of Niraparib by Simultaneous Administration of a 14C-Microtracer and Therapeutic Dose in Cancer Patients. Cancer Chemother Pharmacol (2018) 1:39-46. doi: $10.1007 / \mathrm{s} 00280-017-3455-\mathrm{x}$

90. Saad F, Chi KN, Shore ND, Graff JN, Posadas EM, Lattouf J-B, et al. Niraparib With Androgen Receptor-Axis-Targeted Therapy in Patients With Metastatic Castration-Resistant Prostate Cancer: Safety and Pharmacokinetic Results From a Phase 1b Study (BEDIVERE). Cancer Chemother Pharmacol (2021) 1:25-37. doi: 10.1007/s00280-021-04249-7

91. Matulonis UA, Walder L, Nøttrup TJ, Bessette P, Mahner S, Gil-Martin M, et al. Niraparib Maintenance Treatment Improves Time Without Symptoms or Toxicity (TWiST) Versus Routine Surveillance in Recurrent Ovarian Cancer: A TWiST Analysis of the ENGOT-OV16/NOVA Trial. J Clin Oncol (2019) 34:3183-91. doi: 10.1200/JCO.19.00917

92. Wang Z, Sun K, Xiao Y, Feng B, Mikule KM, Carew J, et al. Niraparib Activates Interferon Signaling and Potentiates Anti-PD-1 Antibody Efficacy in Tumor Models. Sci Rep (2019) 9:1853. doi: 10.1038/s41598-019-38534-6

93. Bahar E, Kim J-Y, Kim D-C, Kim H-S, Yoon H. Combination of Niraparib, Cisplatin and Twist Knockdown in Cisplatin-Resistant Ovarian Cancer Cells Potentially Enhances Synthetic Lethality Through ER-Stress Mediated Mitochondrial Apoptosis Pathway. Int J Mol Sci (2021) 8:3916. doi: 10.3390/ijms 22083916

94. del Campo JM, Matulonis UA, Malander S, Provencher D, Mahner S, Follana P, et al. Niraparib Maintenance Therapy in Patients With Recurrent Ovarian Cancer After a Partial Response to the Last PlatinumBased Chemotherapy in the ENGOT-OV16/NOVA Trial. J Clin Oncol (2019) 32:2968-73. doi: 10.1200/JCO.18.02238

95. Konstantinopoulos PA, Waggoner S, Vidal GA, Mita M, Moroney JW, Holloway R, et al. Single-Arm Phases 1 and 2 Trial of Niraparib in Combination With Pembrolizumab in Patients With Recurrent PlatinumResistant Ovarian Carcinoma. JAMA Oncol (2019) 8:1141-9. doi: 10.1001/ jamaoncol.2019.1048

96. Vinayak S, Tolaney SM, Schwartzberg L, Mita M, McCann G, Tan AR, et al. Open-Label Clinical Trial of Niraparib Combined With Pembrolizumab for Treatment of Advanced or Metastatic Triple-Negative Breast Cancer. JAMA Oncol (2019) 8:1132-40. doi: 10.1001/jamaoncol.2019.1029

97. Vitiello PP, Martini G, Mele L, Giunta EF, De Falco V, Ciardiello D, et al. Vulnerability to Low-Dose Combination of Irinotecan and Niraparib in ATM-Mutated Colorectal Cancer. J Exp Clin Cancer Res (2021) 40:15. doi: 10.1186/s13046-020-01811-8

98. Herman SEM, Montraveta A, Niemann CU, Mora-Jensen H, Gulrajani M, Krantz F, et al. The Bruton's Tyrosine Kinase (BTK) Inhibitor Acalabrutinib Demonstrates Potent on-Target Effects and Efficacy in Two Mouse Models of Chronic Lymphocytic Leukemia. Clin Cancer Res (2017) 11:2831-41. doi: 10.1158/1078-0432.CCR-16-0463

99. Wang M, Rule S, Zinzani PL, Goy A, Casasnovas O, Smith SD, et al. Acalabrutinib in Relapsed or Refractory Mantle Cell Lymphoma (ACE-LY004): A Single-Arm, Multicentre, Phase 2 Trial. Lancet (2018) 10121:659-67. doi: $10.1016 / \mathrm{S} 0140-6736(17) 33108-2$

100. Isaac K, Mato AR. Acalabrutinib and Its Therapeutic Potential in the Treatment of Chronic Lymphocytic Leukemia: A Short Review on Emerging Data. Cancer Manag Res (2020) 12:2079-85. doi: 10.2147/CMAR.S219570

101. Awan FT, Schuh A, Brown JR, Furman RR, Pagel JM, Hillmen P, et al. Acalabrutinib Monotherapy in Patients With Chronic Lymphocytic Leukemia Who Are Intolerant to Ibrutinib. Blood Adv (2019) 9:1553-62. doi: 10.1182/bloodadvances.2018030007

102. Patel VK, Lamothe B, Ayres ML, Gay J, Cheung J, Balakrishnan K, et al. Pharmacodynamics and Proteomic Analysis of Acalabrutinib Therapy: Similarity of On-Target Effects to Ibrutinib and Rationale for Combination Therapy. Leukemia (2018) 4:920-30. doi: 10.1038/leu.2017.321
103. Appleby N, Eyre TA, Cabes M, Jackson A, Boucher R, Yates F, et al. The STELLAR Trial Protocol: A Prospective Multicentre Trial for Richter's Syndrome Consisting of a Randomised Trial Investigation CHOP-R With or Without Acalabrutinib for Newly Diagnosed RS and a Single-Arm Platform Study for Evaluation of Novel Agents in Relapsed Disease. BMC Cancer (2019) 19:471. doi: 10.1186/s12885-019-5717-y

104. Qin JS, Johnstone TG, Baturevych A, Hause RJ, Ragan SP, Clouser CR, et al. Antitumor Potency of an Anti-CD19 Chimeric Antigen Receptor T-Cell Therapy, Lisocabtagene Maraleucel in Combination With Ibrutinib or Acalabrutinib. J Immunother (2020) 4:107-20. doi: 10.1097/CJI.0000000000000307

105. Sharman JP, Egyed M, Jurczak W, Skarbnik A, Pagel JM, Flinn IW, et al. Acalabrutinib Plus Obinutuzumab in Treatment-Naïve and Relapsed/ Refractory Chronic Lymphocytic Leukemia. Cancer Discovery (2020) 3:394-405. doi: 10.1016/S0140-6736(20)30262-2

106. Sharman JP, Egyed M, Jurczak W, Skarbnik A, Pagel JM, Flinn IW, et al. Acalabrutinib With or Without Obinutuzumab Versus Chlorambucil and Obinutuzumab for Treatment-Naive Chronic Lymphocytic Leukaemia (ELEVATE-TN): A Randomised, Controlled, Phase 3 Trial. Lancet (2020) 10232:1278-91. doi: 10.1016/S0140-6736(20)30262-2

107. Stone RM, Mandrekar SJ, Sanford BL, Laumann K, Geyer S, Bloomfield CD, et al. Midostaurin Plus Chemotherapy for Acute Myeloid Leukemia With a FLT3 Mutation. N Engl J Med (2017) 5:454-64. doi: 10.1056/NEJMoal614359

108. Ma J, Zhao S, Qiao X, Knight T, Edwards H, Polin L, et al. Inhibition of Bcl-2 Synergistically Enhances the Antileukemic Activity of Midostaurin and Gilteritinib in Preclinical Models of FLT3-Mutated Acute Myeloid Leukemia. Clin Cancer Res (2019) 22:6815-26. doi: 10.1158/1078-0432.CCR-19-0832

109. Weisberg EL, Puissant A, Stone R, Sattler M, Buhrlage SJ, Yang J, et al. Characterization of Midostaurin as a Dual Inhibitor of FLT3 and SYK and Potentiation of FLT3 Inhibition Against FLT3-ITD-Driven Leukemia Harboring Activated SYK Kinase. Oncotarget (2017) 32:52026-44. doi: 10.18632 /oncotarget.19036

110. Seipel K, Marques MAT, Sidler C, Mueller BU, Pabst T. MDM2- and FLT3Inhibitors in the Treatment of FLT3-ITD Acute Myeloid Leukemia, Specificity and Efficacy of NVP-HDM201 and Midostaurin. Haematologica (2018) 11:1862-72. doi: 10.3324/haematol.2018.191650

111. Ji N, Yang Y, Cai C-Y, Wang J-Q, Lei Z-N, Wu Z-X, et al. Midostaurin Reverses ABCB1-Mediated Multidrug Resistance, an In Vitro Study. Front Oncol (2019) 9:514. doi: 10.3389/fonc.2019.00514

112. Weisberg E, Meng C, Case AE, Tiv HL, Gokhale PC, Buhrlage SJ, et al. Effects of the Multi-Kinase Inhibitor Midostaurin in Combination With Chemotherapy in Models of Acute Myeloid Leukaemia. J Cell Mol Med (2020) 5:2968-80. doi: $10.1111 / \mathrm{jcmm} .14927$

113. Lübke J, Naumann N, Kluger S, Schwaab J, Metzgeroth G, Evans E, et al. Inhibitory Effects of Midostaurin and Avapritinib on Myeloid Progenitors Derived From Patients With KIT D816V Positive Advanced Systemic Mastocytosis. Leukemia (2019) 5:1195-205. doi: 10.1038/s41375-019-0450-8

114. Ctortecka C, Palve V, Kuenzi BM, Fang B, Sumi NJ, Izumi V, et al. Functional Proteomics and Deep Network Interrogation Reveal a Complex Mechanism of Action of Midostaurin in Lung Cancer Cells*. Mol Cell Proteomics (2018) 12:2434-47. doi: 10.1074/mcp.RA118.000713

115. Van Cutsem E, Huijberts S, Grothey A, Yaeger R, Cuyle P-J, Elez E, et al. Binimetinib, Encorafenib, and Cetuximab Triplet Therapy for Patients With BRAF V600E-Mutant Metastatic Colorectal Cancer: Safety Lead-In Results From the Phase III BEACON Colorectal Cancer Study. J Clin Oncol (2019) 17:1460-9. doi: 10.1200/JCO.18.02459

116. Pickles OJ, Drozd A, Tee L, Beggs AD, Middleton GW. Paradox Breaker BRAF Inhibitors Have Comparable Potency and MAPK Pathway Reactivation to Encorafenib in BRAF Mutant Colorectal Cancer. Oncotarget (2020) 34:3188-97. doi: 10.18632/oncotarget.27681

117. van Geel RMJM, Tabernero J, Elez E, Bendell JC, Spreafico A, Schuler M, et al. A Phase 1b Dose-Escalation Study of Encorafenib (LGX818) and Cetuximab With or Without Alpelisib in Metastatic BRAF-Mutant Colorectal Cancer. Cancer Discovery (2017) 6:610-9. doi: 10.1158/21598290.CD-16-0795

118. Hamid O, Cowey CL, Offner M, Faries M, Carvajal RD. Efficacy, Safety, and Tolerability of Approved Combination BRAF and MEK Inhibitor Regimens for BRAF-Mutant Melanoma. Cancers (Basel) (2019) 11:1642. doi: 10.3390/ cancers 11111642 
119. Sun J, Zager JS, Eroglu Z. Encorafenib/binimetinib for the Treatment of BRAF-Mutant Advanced, Unresectable, or Metastatic Melanoma: Design, Development, and Potential Place in Therapy. Onco Targets Ther (2018) 11:9081-9. doi: 10.2147/OTT.S171693

120. Holbrook K, Lutzky J, Davies MA, Davis JM, Glitza IC, Amaria RN, et al. Intracranial Antitumor Activity With Encorafenib Plus Binimetinib in Patients With Melanoma Brain Metastases: A Case Series. Cancer (2020) 3:523-30. doi: $10.1002 /$ cncr.32547

121. Ross KC, Chin KF, Kim D, Marion CD, Yen TJ, Bhattacharjee V. Methotrexate Sensitizes Drug-Resistant Metastatic Melanoma Cells to BRAF V600E Inhibitors Dabrafenib and Encorafenib. Oncotarget (2018) 17:13324-36. doi: 10.18632/oncotarget.24341

122. Choe S, Wang H, DiNardo CD, Stein EM, de Botton S, Roboz GJ, et al. Molecular Mechanisms Mediating Relapse Following Ivosidenib Monotherapy in IDH1-Mutant Relapsed or Refractory AML. Blood Adv (2020) 9:1894-905. doi: 10.1182/bloodadvances.2020001503

123. Abou-Alfa PGK, Macarulla T, Javle PMM, Kelley RK, Lubner SJ, Adeva J, et al. Ivosidenib in IDH1-Mutant, Chemotherapy-Refractory Cholangiocarcinoma (ClarIDHy): A Multicentre, Randomised, DoubleBlind, Placebo-Controlled, Phase 3 Study. Lancet Oncol (2020) 29:796-807. doi: 10.1016/S1470-2045(20)30157-1

124. Tap WD, Villalobos VM, Cote GM, Burris H, Janku F, Mir O, et al. Phase I Study of the Mutant IDH1 Inhibitor Ivosidenib: Safety and Clinical Activity in Patients With Advanced Chondrosarcoma. J Clin Oncol (2020) 15:1693701. doi: $10.1200 /$ JCO. 19.02492

125. Fan B, Mellinghoff IK, Wen PY, Lowery MA, Goyal L, Tap WD, et al. Ivosidenib or Enasidenib Combined With Intensive Chemotherapy in Patients With Newly Diagnosed AML: A Phase 1 Study. Blood (2021) 13:1792-803. doi: 10.1007/s10637-019-00771-x

126. Stein EM, DiNardo CD, Fathi AT, Mims AS, Pratz KW, Savona MR, et al. Clinical Pharmacokinetics and Pharmacodynamics of Ivosidenib, an Oral, Targeted Inhibitor of Mutant IDH1, in Patients With Advanced Solid Tumors. Invest New Drugs (2020) 2:433-44. doi: 10.1182/blood.2020007233

127. Mellinghoff I, Cloughesy T, Wen P, Taylor J, Maher E, Arrillaga-Romany I, et al. ACTR-66. A PHASE 1, OPEN-LABEL, PERIOPERATIVE STUDY OF Ivosidenib (AG-120) AND VORASIDENIB (AG-881) IN RECURRENT IDH1 MUTANT, LOW-GRADE GLIOMA: UPDATED RESULTS. Neuro Oncol (2019) 6:vi28-9. doi: 10.1093/neuonc/noz175.107

128. Faia KConceptualization, Data curation, Investigation, Methodology and Supervision, et al. The Phosphoinositide-3 Kinase (PI3K)- $\delta, \gamma$ Inhibitor, Duvelisib Shows Preclinical Synergy With Multiple Targeted Therapies in Hematologic Malignancies. PloS One (2018) 8:e0200725. doi: 10.1371/ journal.pone. 0200725

129. Flinn IW, Hillmen P, Montillo M, Nagy Z, Illés Á, Etienne G, et al. The Phase 3 DUO Trial: Duvelisib vs Ofatumumab in Relapsed and Refractory CLL/ SLL. Blood (2018) 23:2446-55. doi: 10.1182/blood-2018-05-850461

130. Patel VM, Balakrishnan K, Douglas M, Tibbitts T, Xu EY, Kutok JL, et al. Duvelisib Treatment Is Associated With Altered Expression of Apoptotic Regulators That Helps in Sensitization of Chronic Lymphocytic Leukemia Cells to Venetoclax (ABT-199). Leukemia (2017) 9:1872-81. doi: 10.1038/ leu.2016.382

131. Davids MS, Fisher DC, Tyekucheva S, McDonough M, Hanna J, Lee B, et al. A Phase 1b/2 Study of Duvelisib in Combination With FCR (DFCR) for Frontline Therapy for Younger CLL Patients. Leukemia (2021) 35(4):106472. doi: 10.1182/blood-2018-05-850461

132. Kizilbash SH, Gupta SK, Chang K, Kawashima R, Parrish KE, Carlson BL, et al. Restricted Delivery of Talazoparib Across the Blood-Brain Barrier Limits the Sensitizing Effects of Poly (ADP-Ribose) Polymerase Inhibition on Temozolomide Therapy in Glioblastoma. Mol Cancer Ther (2017) 12:2735-46. doi: 10.1158/1535-7163.MCT-17-0365

133. Lesueur P, Chevalier F, El-Habr EA, Junier M-P, Chneiweiss H, Castera L, et al. Radiosensitization Effect of Talazoparib, a Parp Inhibitor, on Glioblastoma Stem Cells Exposed to Low and High Linear Energy Transfer Radiation. Sci Rep (2018) 8:3664. doi: 10.1038/s41598-018-22022-4

134. Jia $\mathrm{Y}$, Jin $\mathrm{H}$, Gao L, Yang X, Wang F, Ding H, et al. A Novel lncRNA PLK4 Up-Regulated by Talazoparib Represses Hepatocellular Carcinoma Progression by Promoting YAP-Mediated Cell Senescence. J Cell Mol Med (2020) 24(9):5304-16. doi: $10.1111 / j \mathrm{cmm} .15186$
135. Hoffman J, Chakrabarti J, Plotka A, Naraine AM, Kanamori D, Moroose R, et al. Talazoparib has No Clinically Relevant Effect on QTc Interval in Patients With Advanced Solid Tumors. Anticancer Drugs (2019) 5:523-32. doi: 10.1097/CAD.0000000000000772

136. Laird JH, Lok BH, Ma J, Bell A, de Stanchina E, Poirier JT, et al. Talazoparib Is a Potent Radiosensitizer in Small Cell Lung Cancer Cell Lines and Xenografts. Clin Cancer Res (2018) 24(20):5143-52. doi: 10.1158/1078-0432.CCR-18-0401

137. Elmeliegy M, Láng I, Smolyarchuk EA, Chung C-H, Plotka A, Shi H, et al. Evaluation of the Effect of P-Glycoprotein Inhibition and Induction on Talazoparib Disposition in Patients With Advanced Solid Tumours. Br J Clin Pharmacol (2020) 86(4):771-8. doi: 10.1111/bcp.14178

138. Jonuscheit $\mathrm{S}$, Jost $\mathrm{T}$, Gajdošová $\mathrm{F}$, Wrobel $\mathrm{M}$, Hecht $\mathrm{M}$, Fietkau R, et al. PARP Inhibitors Talazoparib and Niraparib Sensitize Melanoma Cells to Ionizing Radiation. Genes (Basel) (2021) 6:849. doi: 10.3390/genes12060849

139. Kohl V, Flach J, Naumann N, Brendel S, Kleiner H, Weiss C, et al. Antileukemic Efficacy in Vitro of Talazoparib and APE1 Inhibitor III Combined With Decitabine in Myeloid Malignancies. Cancers (Basel) (2019) 11(10):1493. doi: 10.3390/cancers 11101493

140. Chen W, Jin D, Shi Y, Zhang Y, Zhou H, Li G. The Underlying Mechanisms of Lorlatinib Penetration Across the Blood-Brain Barrier and the Distribution Characteristics of Lorlatinib in the Brain. Cancer Med (2020) 12:4350-9. doi: 10.1002/cam4.3061

141. Elleraas J, Ewanicki J, Johnson TW, Sach NW, Collins MR, Richardson PF. Conformational Studies and Atropisomerism Kinetics of the ALK Clinical Candidate Lorlatinib (PF-06463922) and Desmethyl Congeners. Angewandte Chem (2016) 128:3654-9. doi: 10.1002/anie.201509240

142. Sakamoto MR, Honce JM, Lindquist DL, Camidge DR. Lorlatinib Salvages CNS Relapse in ALK-Positive Non-Small-Cell Lung Cancer Patient Previously Treated With Crizotinib and High-Dose Brigatinib. Clin Lung Cancer (2019) 2:e133-6. doi: 10.1016/j.cllc.2018.11.010

143. Shaw AT, Solomon BJ, Besse B, Bauer TM, Lin C-C, Soo RA, et al. ALK Resistance Mutations and Efficacy of Lorlatinib in Advanced Anaplastic Lymphoma Kinase-Positive Non-Small-Cell Lung Cancer. J Clin Oncol (2019) 16:1370-9. doi: 10.1200/JCO.18.02236

144. Pirker R, Filipits M. From Crizotinib to Lorlatinib: Continuous Improvement in Precision Treatment of ALK-Positive Non-Small Cell Lung Cancer. ESMO Open (2019) 5:e000548. doi: 10.1136/esmoopen-2019-000548

145. Shaw AT, Felip E, Bauer TM, Besse B, Navarro A, Postel-Vinay S, et al. Lorlatinib in ALK- or ROS1-Rearranged Non-Small Cell Lung Cancer: An International, Multicenter, Open-Label Phase 1 Trial. Lancet Oncol (2017) 12:1590-9. doi: 10.1016/S1470-2045(17)30680-0

146. Sehgal K, Piper-Vallillo AJ, Viray H, Khan AM, Rangachari D, Costa DB. Cases of ROS1-Rearranged Lung Cancer: When to Use Crizotinib, Entrectinib, Lorlatinib, and Beyond? Precis Cancer Med (2020) 3:17. doi: $10.21037 / \mathrm{pcm}-2020$-potb-02

147. Yoda S, Lin JJ, Lawrence MS, Burke BJ, Friboulet L, Langenbucher A, et al. Sequential ALK Inhibitors Can Select for Lorlatinib-Resistant Compound ALK Mutations in ALK-Positive Lung Cancer. Cancer Discovery (2018) 6:714-29. doi: 10.1158/2159-8290.CD-17-1256

148. Genova BRC, Crinò L, Libra M, Leonardi GC. Antitumor Activity of Larotrectinib in Tumors Harboring NTRK Gene Fusions: A Short Review on the Current Evidence. Onco Targets Ther (2019) 12:3171-9. doi: 10.2147/OTT.S177051

149. DuBois SG, Laetsch TW, Federman N, Turpin BK, Albert CM, Nagasubramanian R, et al. The Use of Neoadjuvant Larotrectinib in the Management of Children With Locally Advanced TRK Fusion Sarcomas. Cancer (2018) 21:4241-7. doi: 10.1002/cncr.31701

150. Laetsch TW, DuBois SG, Mascarenhas L, Turpin B, Federman N, Albert CM, et al. Larotrectinib for Paediatric Solid Tumours Harbouring NTRK Gene Fusions: A Multicentre, Open-Label, Phase 1 Study. Lancet Oncol (2018) 5:705-14. doi: 10.1016/S1470-2045(18)30119-0

151. Hong DS, DuBois SG, Kummar S, Farago AF, Albert CM, Rohrberg KS, et al. Larotrectinib in Patients With TRK Fusion-Positive Solid Tumours: A Pooled Analysis of Three Phase 1/2 Clinical Trials. Lancet Oncol (2020) 4:531-40. doi: 10.1016/S1470-2045(19)30856-3

152. Wells AE, Mallen AM, Bui MM, Reed DR, Aptee SM. NTRK-1 Fusion in Endocervical Fibroblastic Malignant Peripheral Nerve Sheath Tumor Marking Eligibility for Larotrectinib Therapy: A Case Report. Gynecol Oncol Rep (2019) 28:141-4. doi: 10.1016/j.gore.2019.04.006 
153. Buerki R, Banerjee A, Zamorski A, Cox M, Raber S, Solomon D, et al. HGG-15. Successful Treatment of an NTRK-Fusiom Positive Infantile Glioblastoma With Larotrectinib, A Targeted TRK Inhibitor. Neuro Oncol (2019) 21:ii89-90. doi: 10.1093/neuonc/noz036.109

154. Nardi V, Ku N, Frigault MJ, Dubuc AM, Tsai H, Amrein PC, et al. Clinical Response to Larotrectinib in Adult Philadelphia Chromosome-Like ALL With Cryptic ETV6-NTRK3 Rearrangement. Blood Adv (2020) 1:106-11. doi: 10.1016/j.leukres.2019.02.012

155. Gerds AT, Tauchi T, Ritchie E, Deininger M, Jamieson C, Mesa R, et al. Phase 1/2 Trial of Glasdegib in Patients With Primary or Secondary Myelofibrosis Previously Treated With Ruxolitinib. Leuk Res (2019) 79:3844. doi: 10.1016/j.leukres.2019.02.012

156. Thompson DL, Moore DC. Glasdegib: A Novel Hedgehog Pathway Inhibitor for Acute Myeloid Leukemia. J Adv Pract Oncol (2020) 2:196-200. doi: 10.6004/jadpro.2020.11.2.8 PharmD, BCPS, BCOP, DPLA.

157. Shaik N, LaBadie RR, Hee B, Chan G. Evaluation of the Impact of Renal Impairment on the Pharmacokinetics of Glasdegib in Otherwise Healthy Volunteers. Cancer Chemother Pharmacol (2021) 2:241-50. doi: 10.1007/s00280-020-04207-9

158. Relias V, McBride A, Newman MJ, Paul S, Saneeymehri S, Stanislaus G, et al. Glasdegib Plus Low-Dose Cytarabine for Acute Myeloid Leukemia: Practical Considerations From Advanced Practitioners and Pharmacists. J Oncol Pharm Pract (2021) 3:658-72. doi: 10.1177/1078155220973737

159. Heuser M, Smith BD, Fiedler W, Sekeres MA, Cortes JE. Clinical Benefit of Glasdegib Plus Low-Dose Cytarabine in Patients With De Novo and Secondary Acute Myeloid Leukemia: Long-Term Analysis of a Phase II Randomized Trial. Ann Hematol (2021) 5:1181-94. doi: 10.1007/s00277-021-04465-4

160. Cortes JE, Heidel FH, Hellmann A, Fiedler W, Smith BD, Robak T, et al. Randomized Comparison of Low Dose Cytarabine With or Without Glasdegib in Patients With Newly Diagnosed Acute Myeloid Leukemia or High-Risk Myelodysplastic Syndrome. Leukemia (2019) 2:379-89. doi: 10.1038/s41375-018-0312-9

161. Tam CS, Opat S, Simpson D, Cull G, Munoz J, Phillips TJ, et al. Zanubrutinib for the Treatment of Relapsed or Refractory Mantle Cell Lymphoma. Blood $A d v$ (2021) 12:2577-85. doi: 10.1182/bloodadvances.2020004074

162. Kaliamurthi S, Selvaraj G, Selvaraj C, Singh SK, Wei D-Q, Peslherbe GH. Structure-Based Virtual Screening Reveals Ibrutinib and Zanubrutinib as Potential Repurposed Drugs Against COVID-19. Int J Mol Sci (2021) 13:7071. doi: 10.3390/ijms22137071

163. Tam CS, Opat S, D'Sa S, Jurczak W, Lee H-P, Cull G, et al. A Randomized Phase 3 Trial of Zanubrutinib vs Ibrutinib in Symptomatic Waldenström Macroglobulinemia: The ASPEN Study. Blood (2020) 18:2038-50. doi: 10.1182/blood.2020006844

164. Wong J, Cher L, Griffiths J, Cohen A, Huang J, Wang L, et al. Efficacy of Zanubrutinib in the Treatment of Bing-Neel Syndrome. Hemasphere (2018) 6:e155. doi: 10.1097/HS9.0000000000000155

165. Flinsenberg TWH, Tromedjo CC, Hu N, Liu Y, Guo Y, Thia KYT, et al. Differential Effects of BTK Inhibitors Ibrutinib and Zanubrutinib on NK-Cell Effector Function in Patients With Mantle Cell Lymphoma. Haematologica (2020) 2:e76-9. doi: 10.3324/haematol.2019.220590

166. Tam CS, Trotman J, Opat S, Burger JA, Cull G, Gottlieb D, et al. Phase 1 Study of the Selective BTK Inhibitor Zanubrutinib in B-Cell Malignancies and Safety and Efficacy Evaluation in CLL. Blood (2019) 11:851-9. doi: 10.1182/blood.2019001160

167. Tarantelli C, Zhang L, Curti E, Gaudio E, Spriano F, Priebe V, et al. The Bruton Tyrosine Kinase Inhibitor Zanubrutinib (BGB-3111) Demonstrated Synergies With Other Anti-Lymphoma Targeted Agents. Haematologica (2019) 7:e307-9. doi: 10.3324/haematol.2018.214759

168. Tam CS, Quach H, Nicol A, Badoux X, Rose H, Prince HM, et al. Zanubrutinib (BGB-3111) Plus Obinutuzumab in Patients With Chronic Lymphocytic Leukemia and Follicular Lymphoma. Blood Adv (2020) 19:4802-11. doi: 10.1182/bloodadvances.2020002183

169. Sugawara T, Baumgart SJ, Nevedomskaya E, Reichert K, Steuber H, Lejeune P, et al. Darolutamide Is a Potent Androgen Receptor Antagonist With Strong Efficacy in Prostate Cancer Models. Int J Cancer (2019) 5:1382-94. doi: 10.1002/ijc.32242

170. Nyknen P, Korjamo T, Gieschen H, Zurth C, Koskinen M. Pharmacokinetics of Darolutamide, Its Diastereomers and Active Metabolite in the Mouse: Response to Saini NK. Drug Metab Lett (2021) 14:9-16. doi: 10.2174/ 1872312814666201112121129
171. Lallous N, Snow O, Sanchez C, Nuñez AKP, Sun B, Hussain A, et al. Evaluation of Darolutamide (ODM201) Efficiency on Androgen Receptor Mutants Reported to Date in Prostate Cancer Patients. Cancers (Basel) (2021) 12:2939. doi: 10.3390/cancers13122939

172. Baumgart SJ, Nevedomskaya E, Lesche R, Newman R, Mumberg D, Haendler B. Darolutamide Antagonizes Androgen Signaling by Blocking Enhancer and SuperEnhancer Activation. Mol Oncol (2020) 9:2022-39. doi: 10.1002/1878-0261.12693

173. Gupta S, Pungsrinont T, Ženata O, Neubert L, Vrzal R, Baniahmad A. Interleukin-23 Represses the Level of Cell Senescence Induced by the Androgen Receptor Antagonists Enzalutamide and Darolutamide in Castration-Resistant Prostate Cancer Cells. Horm Cancer (2020) 3:182-90. doi: 10.1007/s12672-020-00391-5

174. Gupta S, Pungsrinont T, Ženata O, Neubert L, Vrzal R, Baniahmad A. DrugDrug Interaction Potential of Darolutamide: In Vitro and Clinical Studies. Eur J Drug Metab Pharmacokinet (2019) 6:747-59. doi: 10.1007/s12672-020-00391-5

175. Uemura H, Matsushima H, Kobayashi K, Mizusawa H, Nishimatsu H, Fizazi $\mathrm{K}$, et al. Efficacy and Safety of Darolutamide in Japanese Patients With Nonmetastatic Castration-Resistant Prostate Cancer: A Sub-Group Analysis of the Phase III ARAMIS Trial. Int J Clin Oncol (2021) 3:578-90. doi: 10.1007/s10147-020-01824-5

176. Mori K, Mostafaei H, Pradere B, Sari Motlagh R, Quhal F, Laukhtina E, et al. Apalutamide, Enzalutamide, and Darolutamide for Non-Metastatic CastrationResistant Prostate Cancer: A Systematic Review and Network Meta-Analysis. Int J Clin Oncol (2020) 11:1892-900. doi: 10.1007/s10147-020-01777-9

177. Chen I-C, Hsiao L-P, Huang I-W, Yu H-C, Yeh L-C, Lin C-H, et al. Phosphatidylinositol-3 Kinase Inhibitors, Buparlisib and Alpelisib, Sensitize Estrogen Receptor-Positive Breast Cancer Cells to Tamoxifen. Sci Rep (2017) 7:9842. doi: 10.1038/s41598-017-10555-Z

178. Bhutani P, Joshi G, Raja N, Bachhav N, Rajanna PK, Bhuta H, et al. US FDA Approved Drugs From 2015-June 2020: A Perspective. J Med Chem (2021) 64(5):2339-81. doi: 10.1021/acs.jmedchem.0c01786

179. Kirstein AS, Augustin A, Penke M, Cea M, Körner A, Kiess W, et al. The Novel Phosphatidylinositol-3-Kinase (PI3K) Inhibitor Alpelisib Effectively Inhibits Growth of PTEN-Haploinsufficient Lipoma Cells. Cancers (Basel) (2019) 10:1586. doi: 10.3390/cancers11101586

180. Kim K-J, Kim J-W, Sung JH, Suh KJ, Lee JY, Kim SH, et al. PI3K-Targeting Strategy Using Alpelisib to Enhance the Antitumor Effect of Paclitaxel in Human Gastric Cancer. Sci Rep (2020) 10:12308. doi: 10.1038/s41598-020-68998-w

181. Konstantinopoulos PA, Barry WT, Birrer M, Westin SN, Cadoo KA, Shapiro GI, et al. Olaparib and $\alpha$-Specific PI3K Inhibitor Alpelisib for Patients With Epithelial Ovarian Cancer: A Dose-Escalation and Dose-Expansion Phase $1 \mathrm{~b}$ Trial. Lancet Oncol (2019) 4:570-80. doi: 10.1016/S1470-2045(18)30905-7

182. Wong C-H, Ma BBY, Hui CWC, Lo K-W, Hui EP, Chan ATC. Preclinical Evaluation of Ribociclib and Its Synergistic Effect in Combination With Alpelisib in Non-Keratinizing Nasopharyngeal Carcinoma. Sci Rep (2018) 8:8010. doi: 10.1016/S1470-2045(18)30905-7

183. Bedair A, Mansour FR. Insights Into the FDA 2018 New Drug Approvals. Curr Drug Discovery Technol (2021) 18(2):293-306. doi: 10.2174/1570163816666191202104315

184. Kinch MS, Griesenauer RH. 2017 in Review: FDA Approvals of New Molecular Entities. Drug Discovery Today (2018) 23(8):1469-73. doi: 10.1016/j.drudis.2018.05.011

Conflict of Interest: The authors declare that the research was conducted in the absence of any commercial or financial relationships that could be construed as a potential conflict of interest.

Publisher's Note: All claims expressed in this article are solely those of the authors and do not necessarily represent those of their affiliated organizations, or those of the publisher, the editors and the reviewers. Any product that may be evaluated in this article, or claim that may be made by its manufacturer, is not guaranteed or endorsed by the publisher.

Copyright (c) $2021 \mathrm{Chu}, \mathrm{Bu}$ and Yang. This is an open-access article distributed under the terms of the Creative Commons Attribution License (CC BY). The use, distribution or reproduction in other forums is permitted, provided the original author(s) and the copyright owner(s) are credited and that the original publication in this journal is cited, in accordance with accepted academic practice. No use, distribution or reproduction is permitted which does not comply with these terms. 